Portland State University

PDXScholar

Fall 8-23-2013

\title{
Identity Development of Adolescent Gay Black Males
}

Miles James Allen Crumley

Portland State University

Follow this and additional works at: https://pdxscholar.library.pdx.edu/open_access_etds

Part of the African American Studies Commons, and the Lesbian, Gay, Bisexual, and Transgender Studies Commons

Let us know how access to this document benefits you.

\section{Recommended Citation}

Crumley, Miles James Allen, "Identity Development of Adolescent Gay Black Males" (2013). Dissertations and Theses. Paper 1024.

https://doi.org/10.15760/etd.1024

This Thesis is brought to you for free and open access. It has been accepted for inclusion in Dissertations and Theses by an authorized administrator of PDXScholar. Please contact us if we can make this document more accessible: pdxscholar@pdx.edu. 
Identity Development of Adolescent Gay Black Males

by

Miles James Allen Crumley

A thesis submitted in partial fulfillment of the requirements for the degree of

\author{
Master of Science \\ in \\ Interdisciplinary Studies \\ Thesis Committee: \\ Dalton Miller-Jones, Chair \\ Wayne Wakeland \\ Courtney Ann Hanson
}

Portland State University

2013 
(c) 2013 by Miles James Allen Crumley 


\begin{abstract}
During adolescence, self-identified gay black males may develop their identities differently than their gay white male counterparts. This may be attributed to the reconciliation of stressors when developing gay, black, and male identities within certain environmental contexts. To investigate this, twelve qualitative interviews were conducted of gay black males from which developmental themes were extracted. While many of the developmental processes are similar to their white homosexual counterparts, some differences were noted regarding racism, objectification by the white gay community, and use of the internet to develop particular identities. A new theory using dynamic systems theory that includes many complexities of identity development is proposed. A hybrid story-like model was developed to illustrate the roles of lenses and buffers as they pertain to how an identity functions. Lenses allow a person to see their way through a variety of experiences; buffers contain coping mechanisms and skills to alleviate tension from negative experiences. Future research should include other minority groups and women for a more complete picture of identity development processes. This would allow better tools to be built that can be utilized by intervention designers.
\end{abstract}




\section{Dedication}

I would like to dedicate this thesis to all people who are struggling to find themselves. I often tell friends that adolescence is the second most traumatic time in a person's life, with birth being the first. The act of finding oneself and solidifying it all in your head can be a difficult thing to do, especially if you do not fit within society's mold of acceptable behavior. It is naïve to think that there is a normal pathway of development. This thesis, in a way, can serve as a stepping-stone for all adolescents as they navigate through this time period. 


\section{Acknowledgements}

Thank you to Drs. Dalton Miller-Jones and Wayne Wakeland for their significant support in developing the systems model. Also, special thanks to Courtney Ann Hanson for helping me navigate through the graduate process.

And special shout-out to my parents, George and Sharon Crumley, my friends, family, and peers who supported me. 
Contents

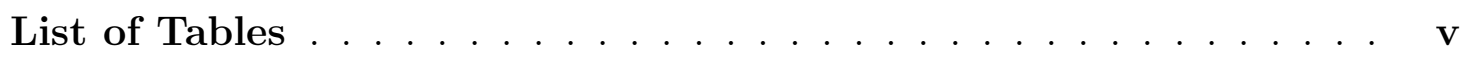

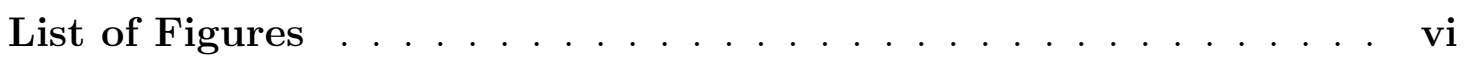

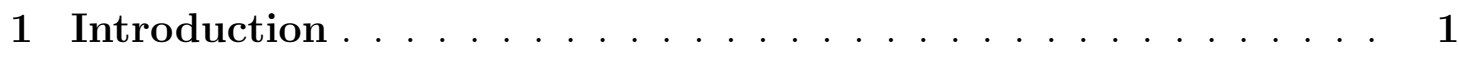

1.1 Introduction . . . . . . . . . . . . . . . . 1

1.2 Conceptual Background . . . . . . . . . . . . . . . . 3

1.3 Motivation of the Study . . . . . . . . . . . . . . . . . 10

1.4 Goals of the Study . . . . . . . . . . . . . . . . . . 11

1.5 Questions of Interest $\ldots \ldots \ldots \ldots$

2 Theoretical Background $\ldots \ldots \ldots \ldots$

2.1 Existing Identity Development Theories . . . . . . . . . . . . . . 14

2.1 .1 Marcia/Erikson . . . . . . . . . . . . . . . . . 15

2.1.2 Bronfenbrenner and Proximal Processes . . . . . . . . . . 17

2.1.3 Phenomenological Variant of Ecological Systems Theory . . 18

2.2 Specific Identity Theories . . . . . . . . . . . . . . . . . 21

2.2 .1 Ethnic Identity . . . . . . . . . . . . . . . . . . . . . 22

2.2 .2 Sexual Identity . . . . . . . . . . . . . . . . . . . 25

2.2 .3 Gender Identity . . . . . . . . . . . . . . . . . . . 29

2.3 Intersections and Shortcomings of Existing Theories . . . . . . . 29

2.4 Dynamic Systems Theory _. . . . . . . . . . . . . . . 32

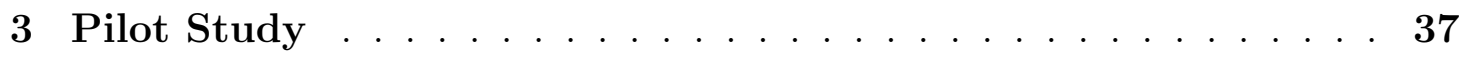

3.1 Pilot Study Description . . . . . . . . . . . . . . . 37

3.2 Methods . . . . . . . . . . . . . . . . . 38

3.3 Results and Analysis . . . . . . . . . . . . . . . . . 40

3.4 Strengths and Limitations _. . . . . . . . . . . . . . 45

4 Part I: Primary Study - Interviews _ . . . . . . . . . . . 49

4.1 Interviews . . . . . . . . . . . . . . . . . . 49

4.2 Methods . . . . . . . . . . . . . . . . . . 51

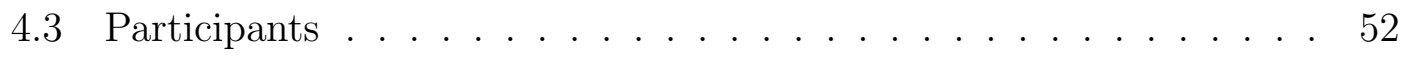




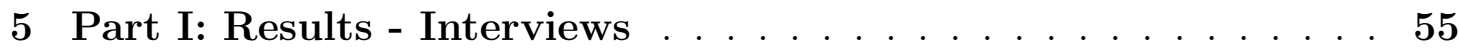

5.1 Interview Results . . . . . . . . . . . . . . . . 55

5.2 Specific Themes . . . . . . . . . . . . . . . 56

5.2 .1 General Identities . . . . . . . . . . . . . . . . . 56

5.2 .2 Gender Identity . . . . . . . . . . . . . . . . . . . 58

5.2 .3 Racial/Ethnic Identity . . . . . . . . . . . . . . . . . . . . 59

5.2 .4 Sexual Identity . . . . . . . . . . . . . . . . . . . 62

5.3 Context Identity Saliency Questionnaire Results . . . . . . . . . . 65

6 Part II: Proposed Theory _. . . . . . . . . . . . . . . . . 69

7 Dynamic Systems Model of Identity . . . . . . . . . . . . . 79

7.1 Causal Loop Diagrams . . . . . . . . . . . . . . . . . 80

7.2 Stock and Flow Diagrams . . . . . . . . . . . . . . 82

7.3 Proposed Hybrid Story-like Model . . . . . . . . . . . . . . . . 83

7.4 Multiple Identities . . . . . . . . . . . . . . . . . . . . 91

8 Discussion and Next Steps . . . . . . . . . . . . . . . 95

8.1 Comparison to Previous Research . . . . . . . . . . . . . 100

8.2 Limitations . . . . . . . . . . . . . . . . . . . . . 102

8.3 Future Research . . . . . . . . . . . . . . . . . . . . . . 102

Bibliography . . . . . . . . . . . . . . . . . . 104

Appendices . . . . . . . . . . . . . . . . . 110

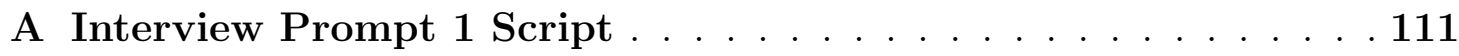

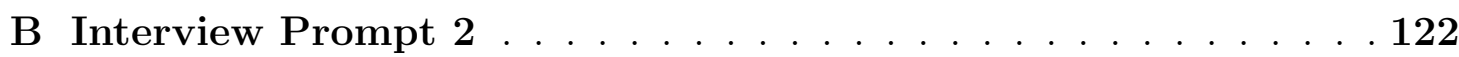

C Institutional Review Board Consent Form . . . . . . . . . . . 133

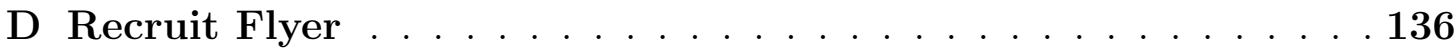


List of Tables

2.1 Proximal Processes for Fire fighting example . . . . . . . . . . . 18

3.1 Pilot Study Participants . . . . . . . . . . . . . . . 38

4.1 Second Study Participants . . . . . . . . . . . . . . . 54

5.1 Mode Statistics for CISQ . . . . . . . . . . . . 67 
List of Figures

2.1 Marcia/Erikson Model of Development . . . . . . . . . . . . . . 16

2.2 Firefighter proximal process diagram . . . . . . . . . . . . . . . 19

2.3 PVEST Model . . . . . . . . . . . . . . . . . . . 36

3.1 Theory Map . . . . . . . . . . . . . . . . . . . 40

3.2 Illustration of Final Model from Pilot Study . . . . . . . . . . . . . 41

3.3 Final Model from Pilot Study . . . . . . . . . . . . . . . . . 48

4.1 PVEST Model Simplified . . . . . . . . . . . . . . 50

5.1 CISQ Total Frequencies ................ 66

6.1 Proposed Theory Diagram . . . . . . . . . . . . . . . . . 71

6.2 Two-Way Model Illustrated . . . . . . . . . . . . . . . . . 73

6.3 Tensor Model . . . . . . . . . . . . . . . . 75

7.1 Causal loop diagram with delay for maintaining temperature . . . . 80

7.2 Behavior versus time plot of water temperature fluctuations. . . . . 81

7.3 Basic archetype of a stock and flow diagram. . . . . . . . . . . . . 82

7.4 Stock and flow diagram of mining mineral deposits. . . . . . . . . . 82

7.5 Stock and flow diagram of energy expenditures. . . . . . . . . . . 83

7.6 Person, Ideal Self, Identity . . . . . . . . . . . . . . . . . 85

7.7 Overlap of current and possible selves as an indicator of strength of identity. . . . . . . . . . . . . . . 86

7.8 Identity shaping lenses and replenishing buffer . . . . . . . . . . . 87

7.9 Proposed Causal Loop Model . . . . . . . . . . . . . . . . . . . . . 89

7.10 Push and Pull of Identity . . . . . . . . . . . . . . . . . . . . . . . . . . . . . . . . . . . . . .

7.11 Overlapping of multiple Ideal selves . . . . . . . . . . . . . . . . . . 92

7.12 Example of varying overlap of ideal selves. . . . . . . . . . . . . 93 


\title{
Chapter 1
}

\author{
Introduction
}

\subsection{Introduction}

This research project and thesis was undertaken to help me better understand myself. Growing up, I found that I often lacked the terminology to describe what I felt, let alone who I was. Growing up as a young, African American male in the south, I recognized that perhaps I had different sexual attractions than my peers but did not have the resources to fully explore my internal sexual feelings. As I interacted with my peers, many of them could not relate to my experience, but significantly, I had to understand theirs. The culture that I lived in was hostile toward those that existed outside the norm of heterosexuality. Living in a racially segregated part of the country further complicated matters, since it was often difficult to determine who was my true ally and who was actively trying to keep me from progressing. The task of finding a supportive group of peers occupied much of my development during adolescence.

In undertaking this project, a primary goal was to understand the things I went through by understanding and documenting how others similar to myself developed their identity. Additionally, I want to offer different resources to youth who 
do not have access to a guide to help them develop into healthy and balanced human beings. While reviewing the academic literature, I sought articles pertaining to psychological adolescent identity development. I was disappointed to learn that previous studies on adolescence, particularly those of ethnic and sexual minorities, have been interested in wedging groups of people apart instead of looking at how individuals function within contexts or cultures. Using terminology created by Susan Harter (1990), the selves that one creates have a specific meaning and functionality for a person but also for those around them. In other words, who I am and how I interact with my surroundings means just as much to me as it does to you.

The focus of this thesis is on the processes that adolescents go through when developing their ethnic, sexual, and gender identities. Specifically of interest are the unexplored processes for gay Black males (Jamil, Harper \& Fernandez, 2009). This population is of interest because it has been traditionally un- or under-represented in psychological research. Some researchers have recognized that this group faces a unique set of challenges when developing identities during adolescence and stress the need to be more inclusive in research on identity and adolescents (Jamil et al., 2009; Poteat, Aragon, Espelage \& Koenig, 2009; Rosario, Schrimshaw \& Hunter, 2004; Spencer, 2006). The processes behind identity development are complex and dynamic, involving biological, cultural (societal), and psychological factors.

This type of development will be conceptualized two ways. The first way will use several existing theories of identity development in adolescence. A new theory will be proposed that couples all of the ideas together into a unified theory that 
can be applied more strategically to different groups of people. The core idea of this new theory comes from the Phenomenological Variant of Ecological Systems Theory, or PVEST, created by Margaret Spencer (2006). This model, combined with several specific theories of ethnic, gender, and sexual identities, will make up the new theory. The second way to conceptualize the formation of identities is to use dynamic systems theory found in the field of systems science (Diamond, 2007; Lewis, 2000). Dynamic systems theory allows for the imposition of a physics-like model on a system that has stable and unstable domains. Arguably, the process of developing an identity is a prime candidate for this type of modeling since adolescents are being bombarded with ideas, expectations, personal motivators, and changing cultural dynamics as they attempt to define who they are in relation to others and society. The synthesis of their inputs can create periods of internal instability followed by periods of stability. Dynamic systems theory has been used to understand language acquisition and other skills of small children (see Lewis, 2000; Thelen, 1989, 2005; van Geert, 1998, 2003; van Geert \& Steenbeek, 2005) but has only been used once to conceptualize the development of an identity (see Diamond, 2007). Using the proposed theory from the first part as a guide, the use of dynamic systems theory to quantify identity development could open the door to developing better interventions for youth.

\subsection{Conceptual Background}

Biologically, adolescence is divided into two periods: puberty and late adolescence. Puberty marks the massive release of hormones throughout the body, 
triggering a second period of physical development. Cognitively, the brain is reorganized as the meaning-making and reasoning parts of the brain develop into more mature forms. Socially, a person in puberty adjusts his peer groups around similar interests and desires. As Newton's third law of motion states, "For every action there is an equal and opposite reaction"; the environment in which a pubescent person exists in begins to interact with the person differently in recognition of their physical and cognitive changes. For example, as a male enters adolescence, his body changes from child-like to teenager-like to adult-like. These changes to the individual means his environment now interacts with him differently (Finkenauer, Engels, Meeus \& Oosterwegel, 2002). Children are generally supervised as they maneuver between school, home, and other activities. Teenagers are given more freedom, such as later curfew, and opportunities to interact with their peers unsupervised. These changes also allow them to excel at sports, writing, or other hobbies of interest. Adults are allowed more freedom and a concurrent set of responsibilities such as paying bills, access to rental cars, and the ability to make personal decisions without parental intervention.

Late adolescence marks the period where the biological changes of puberty continue to have a strong impact on the body. Adolescents have reached a state of sexual (biological) maturity, yet their brains continue to develop as a function of hormonal changes combined with environmental interactions. During late adolescence, adolescents develop their identities, or self-concepts, which will be used for the remainder of their lives (Harter, 1990; Markus \& Nurius, 1986). Identities formed during adolescence help to relieve tension created during adolescence 
and later adulthood, as a person interacts with different environments (Dubé \& Savin-Williams, 1999; Jamil et al., 2009; Rosario et al., 2004; Rotheram-Borus \& Langabeer, 2001). This is done by functioning as a "buffer" and a "lens" between a person and his environment. The main identities of interest are those of gay Black men. This group occupies two minority groups simultaneously, and the issues they face are largely unknown (Jamil et al., 2009; Poteat et al., 2009; Rosario et al., 2004; Spencer, 2006).

According to the bioecological model proposed by Bronfenbrenner \& Morris, proximal processes are a series of interactions between an object and its environment over time (Bronfenbrenner \& Morris, 1998). In Bronfenbrenner's words,

Especially in its early phases, but also throughout the life course, human development takes place through processes of progressively more complex reciprocal interaction between an actively evolving biopsychological human organism and the persons, objects, and symbols in its immediate external environment. To be effective, the interaction must occur on a fairly regular basis over extended periods of time. Such enduring forms of interaction in the immediate environment are referred to as proximal processes. Examples of enduring patterns of proximal process are found in feeding or comforting a baby, playing with a young child, child-child activities, group or solitary play, reading, learning new skills, athletic activities, problem solving, caring for others in distress, making plans, performing complex tasks, and acquiring new knowledge, and know-how. (Bronfenbrenner \& Morris, 1998, p.996)

Many sexual ethnic minorities have a different set of proximal processes than their peers. For example, Jamil et al. (2009) states that many youth now use the internet to find resources to explore their sexual identity. "This was seen as a way to anonymously explore their sexual identity, but also as a way to find mentorship and support with ethnically similar [gay, bisexual, queer] men" (p. 208). A careful 
documentation of these differences could provide insights as to how to provide more supportive environments for all youth.

African American gay men tend to disclose their sexuality less often and to fewer people over time (Dubé \& Savin-Williams, 1999; Jamil et al., 2009; Poteat et al., 2009; Rosario et al., 2004; Savin-Williams, 1998, 2001). This is supported by my own personal experience as well as Dubé \& Savin-Williams (1999) who suggests that ethnic minorities tend to delay disclosing their sexual identity to family members as a familial coping mechanism: "This may reflect their greater fear of rejection and disappointment from family members" (p. 1396). A study by Rosario et al. "found that Black youths were more uncomfortable with others knowing about their homosexuality and had disclosed to fewer [people] than had their White peers" (p. 225). It may be that one's collective ethnic identity provides a better protective buffer against discrimination and prejudice, negating the need to extensively develop a sexual or gender identity (Cross Jr., 1991; Helms, 1990). This might lead African American youth to hide their sexual identity from their larger ethnic communities as a way to prevent themselves from being alienated (Dubé \& Savin-Williams, 1999). The recent vocal opposition and public rejection by Black church leaders of California's gay marriage ballot proposition provides further evidence that these concerns among Black youth are well grounded (Abrajano, 2010).

As the idea of dynamic systems theory has developed over the past few decades, many researchers have applied its principles and modeling schema to different areas of development (see Diamond, 2007; Lewis, 2000; Thelen, 1989, 2005; van 
Geert, 1998, 2003; van Geert \& Steenbeek, 2005). The literature on development and dynamic systems generally falls into two categories: theory-driven models and mathematical models (Lewis, 2000). Many developmental psychologists are not comfortable with the assumptions and math that dynamic systems imposes on psychological phenomena; likewise, many of the mathematical modelers feel uncomfortable only using theory to explain complex non-linear phenomena (Lewis, 2000). However, as psychologists strive to make their theories applicable to more populations, a dynamic systems approach becomes necessary to keep track of variables that were not present in their original theory.

Using dynamic systems theory to develop descriptive models has been used previously by other psychologists. Notably, Diamond uses a dynamic systems approach to describe the identity development in a longitudinal study of lesbians (2007). After analyzing the findings from the their study, Diamond chose this approach to account for the following:

This study has documented notable within-person variability over time, particularly (a) nonlinear discontinuities in women's attractions, behaviors, and identities; (b) the abrupt emergence of novel erotic feelings and experiences in specific contexts; and (c) periodic episodes of reorganization in sexual self-concept at multiple points in the life course. Such phenomena are difficult to reconcile with conventional models of same-sex sexuality, hence they have historically been discounted as idiosyncratic, unexplainable noise in the data on sexual orientation (2007, p.143).

These types of findings are difficult to create linear models from because the behavior does not change steadily over time. In fact, there are multiple nonlinear influences that each have their own meaning to a person that changes over time. 
Dynamic systems theory allows for the generation of models that can account for these constantly changing variables.

This current project research is based, in part, on the assumption that for ethnic minorities, the process of developing a sexual identity is done in private to avoid perceived stressors created by their larger ethnic community. Adolescents, in an attempt to explore their surroundings, create "false selves" (Rotheram-Borus \& Langabeer, 2001). Rotheram-Borus \& Langabeer argue that "in contrast to many of the false selves generated by heterosexual youths, passing by gay, lesbian, and bisexual youths is often a way to avoid serious negative sanctions" (2001, p. 102). Passing is a way for a person to assume the physical characteristics or mannerisms of a dominant group in order to blend in or to deter unwanted negative attention by their preferred identity or identities. This is further complicated by the intersection of sexual identity and ethnicity: Researchers Dubé \& Savin-Williams (1999) suggest many youth "face greater barriers in adjusting to their sexual identity because this identity must be integrated with and accepted in the context of an ethnic identity" (p. 1390). Additionally, Dubé \& Savin-Williams (1999) argue that the difficulty that ethnic minorities face when addressing their sexual identity is due to the fact that one's sexual identity must be integrated into their ethnic identity as well.

The present study also assumes that gay African American males face oppression differently than other groups of people. According to Jamil et al.,

Regarding their ethnic identity, youth indicated that they experienced both direct and indirect forms of racism from the larger White community. They also experienced oppression in the predominately White 
gay community in the form of eroticization and objectification because of their ethnicity and a general lack of inclusion and acceptance. In contrast, youth experienced heterosexism from the larger heterosexual community, in addition to specific acts of oppression [and rejection] from family members, peers, and people in their neighborhood. As a result, youth of color reported facing oppression from a variety of sources, including groups and individuals who may have been able to play a supportive role in one of their identity development processes (2009, p. 211).

These results are consistent with other findings regarding "multiple forms of oppression" (Jamil et al., 2009, p. 211). Sexual and ethnic identities are conceptualized to serve as a way to prevent adolescents from being overly negatively impacted by the stressors they may face. As Jamil et al. states, the type of oppression that adolescents face is contextual and at times may overlap with other areas in their lives.

Recognizing that there are several different theories regarding identity development of different groups of people, it is important to make sure the best theory is used when attempting to understand something as complicated as development. Using the Phenomenological Variant of Ecological Systems Theory as a framework is arguably a good starting point since it incorporates many factors that may play a role in how adolescents develop. Using this organizing framework, one can then use a dynamic systems approach to sharpen the available theory by modeling the outcomes from collected data. 


\subsection{Motivation of the Study}

The background for this study is based in part on a study by Poteat et al. (2009) who designed a study that examined the three-way interaction between race, gender, and sexual orientation. While the study by Poteat et al. (2009) highlights some of the issues that Lesbian, Gay, Bisexual, Transgendered, and Queer (LGBTQ) youth face as they develop, the issues could only be generalized to a White population due to a lack of ethnic minority respondents (Poteat et al., 2009). The purpose of the present study is to employ a methodology that captures the unique experiences of gay African American males. Ideally, this research could then be used to create culturally specific interventions for use by caregivers to adolescents.

Puberty marks the beginning of changes physically, mentally, and socially. Secondary sexual characteristics begin to develop, priming many adolescents to begin to consider exploring sexual relationships with their peers. Katchadourian (1980) argues "that the profound changes in puberty somehow influence the sexual [both gender and sexual] motivation of the adolescent and that such influences operate in a psychosocial context, which also determines how the adolescent behaves sexually." As one begins to develop physically and cognitively, they are suddenly exposed to ever increasingly more complex environments and situations. For many Black boys, the onset of puberty is when they transition from being harmless youngsters to the stereotypical aggressive Black male that should be feared. Being larger in stature, combined with the stereotype of being dangerous, changes how the environment engages and interacts with them. 


\subsection{Goals of the Study}

The purpose of this research project is to better understand the underlying processes that adolescents go through in order to develop their respective identities.

Of particular interest are the processes that gay Black males go through. This population is of interest because of the lack of data regarding this particular group of individuals as well as their unique position within respective cultures. The ongoing legacy of racism in the United States is no mystery, but what is fascinating is how the existing Black community and the dominant white community treat sexual minorities. The resiliency of Black people in general has been documented; however, there have not been many studies to date that examine the resiliency of Black sexual minorities. Understanding how a Black sexual minority navigates this terrain can perhaps shed some light into how adolescents with multiple oppressed identities navigate through this period and ultimately make it to adulthood.

\subsection{Questions of Interest}

The specific questions of interest for this project are:

1. What processes do male, sexual and ethnic minorities go through as they develop their identities during adolescence? What role does the environment play in developing their identities?

2. Do each of the identities of male, sexual and ethnic minorities intersect with one another? Does the intersection of identities cause internal or external conflict? Do these identities complement each other? 
3. What would a dynamic systems model of male, sexual and ethnic identity development that incorporates environmental contexts and influences (i.e. peers, other resources), and biological changes during adolescence, look like? Can a dynamic model add clarity to existing knowledge of identity development of male, sexual and ethnic minorities? Can this model be used to generate new theories that allow for a better understanding of developmental processes of male, sexual and ethnic minorities? 


\section{Chapter 2}

\section{Theoretical Background}

Adolescence is considered the period of time in human development beginning with the onset of puberty to about age 27. Adolescence marks a period of massive biological, psychological, and social development (Harter, 1990; Katchadourian, 1980; Marcia, 1980). As a person develops physically and cognitively, they are suddenly exposed to ever increasingly more complex environments and situations. One of the main goals of adolescence is to create a cohesive identity or self-concept. The development of an identity is a crucial step during the lifespan of a human being. Harter states:

Adolescence represents a fascinating transitional period, marked by the emergence of new found cognitive capacities and changing societal expectations that, in consort, profoundly shape and alter the very nature of the self-concept. Teenagers who successfully navigate the journey of self-development should acquire a clear and consolidated sense of true self that is realistic and internalized, one that will lay the basis for further identity development. Failure to chart these waters successfully may result in a number of potential psychological risks, among them a distorted or unrealistic self-concept, failure to integrate the self across multiple roles, conflict over seeming contradictions within the self, maladaptive or distressing displays of false selves, and definitions of the self that rely primarily on the standards and desires of others. Any one of these may preclude the development of an integrated, internalized sense of self that will foster the search for meaningful future identity (Harter, 1990, pg.353-354). 
Adolescents begin to answer the questions of the self such as "Who am I?" and "Who do I want to be?" "Who am I" refers to the current self while "who do I want to be?" represents all of the possibilities that a person may become (Markus \& Nurius, 1986). In order to answer these questions, adolescents go through a process of experimenting and investigating different possible outcomes. This, combined with their physical nature changing, causes the environment they are embedded within to treat them differently (Finkenauer et al., 2002). By observing and making meaning from interactions with people around them, adolescents begin the process of identity development. An identity, therefore, serves two purposes: first, to serve as a buffer between a person and the outside world; and secondly, as a lens to view and interpret the world around them. An identity also serves as a mental anchor for a person to attach an experience. An identity also encapsulates the different roles that a person has based on their environment(s). This collection of environmentally dependent roles allows an adolescent to answer "What am I?" (Finkenauer et al., 2002, pg. 29).

\subsection{Existing Identity Development Theories}

Several theories currently exist regarding how an identity is formed. These theories are presented in order of increasing complexity, beginning with the most widely accepted identity theory by Erik Erikson and ending with a more contemporary interpretation by Margaret Spencer. 


\subsubsection{Marcia/Erikson}

Identity development has traditionally been viewed from the perspective of a stage type theory. One of the more popular stage theories on adolescence was originally presented by Erik Erikson in 1968 (Marcia, 1980). Marcia (1980) took Erikson's theory and used data from different studies to validate the different stages. According to Marcia (1980), developing an identity occurs in four stages:

Identity Achievements are individuals who have experienced a decisionmaking period and are pursuing self-chosen occupation and ideological goals. Foreclosures are persons who are also committed to occupational and ideological positions, but these have been parentally chosen rather than self-chosen. They show little or no evidence of "crisis." Identity Diffusions are young people who have no set occupational or ideological direction, regardless of whether or not they may have experienced a decision-making period. Moratoriums are individuals who are currently struggling with occupational and/or ideological issues; they are in an identity crisis (Marcia, 1980, p.161).

An adolescent enters the model in the moratorium stage. They actively look around in their environments for cues and clues as to who they want to be as they get older. As they begin to hone in on a more refined set of goals, they then enter the identity diffusion phase. Adolescents generate several answers to the question "who do I want to be" and actively explore different possibilities (Markus \& Nurius, 1986). When a person has decided which pathway to go down, he is now foreclosing on an identity. From here, there is less investigation of other possibilities

but accumulation of the skills necessary to meet the desired goal. Upon reaching this goal, a person then enters into the identity achievement phase. Figure 2.1.1 illustrates Marcia's theory. 


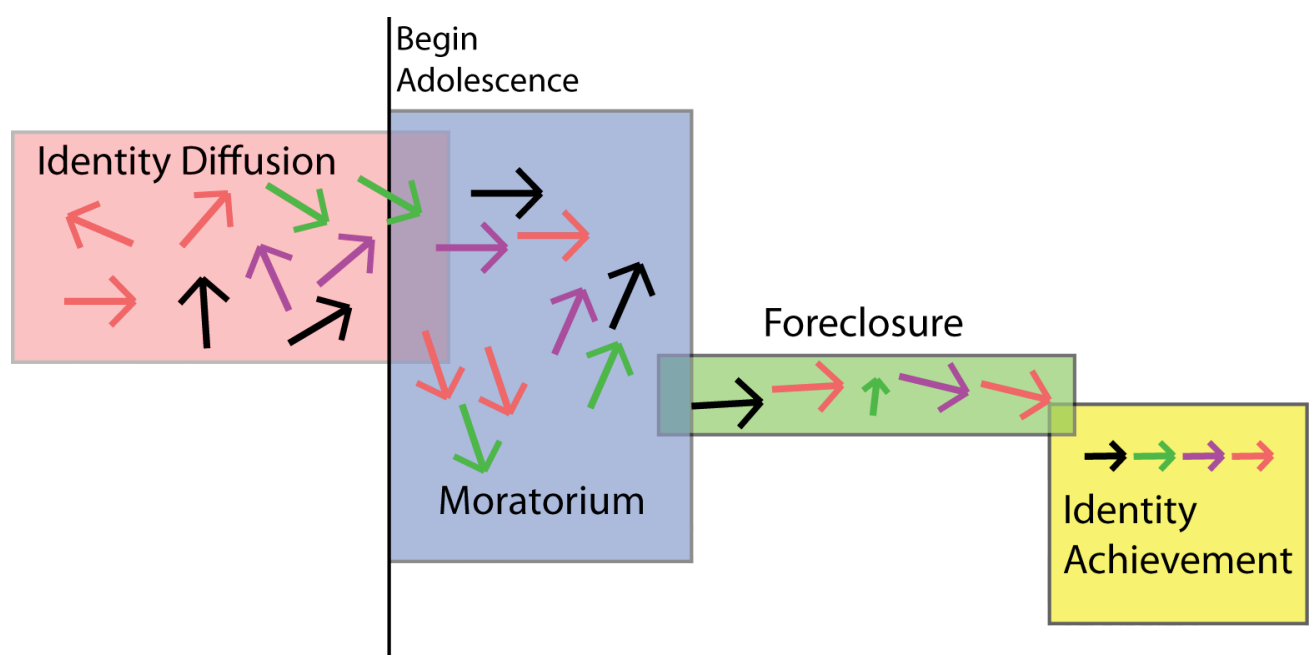

Figure 2.1: The model created by Marcia/Erikson. Each box represents a different stage with the size of the box representing all of the external influences that encompass a person. As an adolescent proceeds through each stage, he is attenuated toward a specific goal or pathway. This attenuation is represented by the aligning of the arrows.

This model is relevant in the general sense but neglects certain environmental factors that influence which possibilities are considered for foreclosure. The model is also unclear as to when one stage ends and when another begins (Marcia, 1980). This can be particularly troublesome for groups that lack adequate environmental resources to have enough data to begin the identity diffusion process. Since many of the models created by early psychologists were created on the normative standard of middle class white men (Spencer, 2006), this model does not include some of the environmental cues specific to women or ethnic minorities (Marcia, 1980). For example, the model does not reveal how stereotypes regarding women in math influence their desire to enter into science and engineering fields. Therefore a new model of identity development should take into consideration the specific processes 
that influence how people develop.

\subsubsection{Bronfenbrenner and Proximal Processes}

Bronfenbrenner \& Morris (1998) introduced ecological systems theory as a way to examine the specific processes that persons go through to develop their identity(ies). In comparison to Marcia/Erikson, this theory focuses on the specifics that allow a person to go from one stage to the next. Bronfenbrenner \& Morris state that in order for development to happen, several things must be in place. First, development can only occur if there is some sort of change over time (Bronfenbrenner \& Morris, 1998). Over time, there must be some change between how a person was previously and now. This can be modeled by the equation state $_{\text {now }} \neq$ state $_{\text {later }}$. The direction of movement can be in any direction as long as a person is in a different place later. Second, development is about finding a point of stability in a particular state (Bronfenbrenner \& Morris, 1998). Third, how one gets from state $_{\text {now }}$ to state $_{\text {later }}$ is with proximal processes. Proximal processes are defined as "interactions between the environment and an organism" (Bronfenbrenner \& Morris, 1998, p. 994).

Proximal processes work in two ways. First, they help to move a person from a stable point to an area of instability. Next, they are the processes used to help a person reach a new stable state. For example, say a child observes a firefighter at work from personal interaction with them; he might create a possible self firefighter. As this child gets older, he might hang out at fire stations and interact with firefighters in his environment. As the child enters adolescence, he might think that being a firefighter is cool because he has an uncle who is a firefighter and his 


\begin{tabular}{c}
\hline List of Proximal Processes \\
\hline Watching firefighters extinguish fire \\
Volunteering at fire station \\
Reading about firefighting in school \\
Discussing firefighting with Uncle \\
Attending firefighting school \\
\hline
\end{tabular}

Table 2.1: Table of Proximal Processes for Youth desiring to be a firefighter

uncle has always been sensitive to his needs growing up. The teenager may then volunteer at the local fire station during his spare time. He might also read books about firefighters. During high school, this person might contact the local fire department and find out the criteria to become a firefighter. After high school, he might graduate and decide to become a firefighter, first attending school and then becoming employed by the local fire department. Table 2.1 gives a summary of the proximal processes in this scenario, and Figure 2.1.2 summarizes how proximal processes helped bring the person from stability to instability to stability.

What the Bronfenbrenner \& Morris model adds to the Marcia/Erikson model is a clearer picture of how a person would theoretically move between stages. The model, however, only provides a general overview of how proximal processes work. It does not take into consideration how different environments can impact or influence the types of proximal processes a person has access to or engages.

\subsubsection{Phenomenological Variant of Ecological Systems Theory}

Spencer, Dupree \& Hartmann (1997) introduced the Phenomenological Variant of Ecological Systems Theory (PVEST) to help fill the gaps in Marcia/Erikson's 


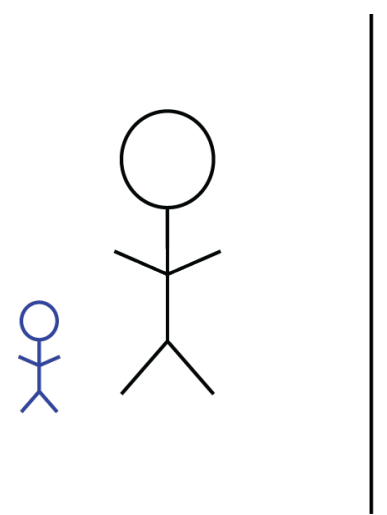

(a)

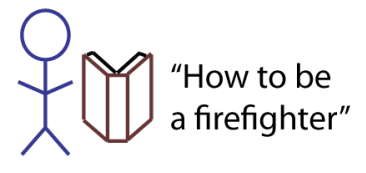

(b)

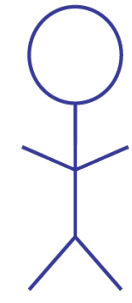

(c)

Figure 2.2: In the figure, (a) a person observes what a firefighter does by hanging out with his uncle; (b) he studies books and goes to firefighting school to train to be a firefighter; and (c) a person becomes a firefighter as an adult.

and Bronfenbrenner's theories. Spencer was primarily interested in the coping mechanisms of African American males and the role the environment had on their development when compared with European descended males. The model takes facets from the previous theories and adds that a person's identity is a direct function of the environment that a person is embedded in and not the converse (Spencer, 2006).

Adopting this view allows for an understanding of complex behaviors of African American youth and other groups. For example, African American youth may react differently to the prospect of higher education if they see that higher education has not served any benefit to those within their immediate environment. Those with higher education in the African American community are still subject to institutionalized racism and challenges that come from living within that system. It may be more feasible to work and survive even if that means functioning at a 
diminished level. For European American youth, however, they may see a benefit to higher education within their environment and may behave differently when presented with the same prospects in higher education. Both views are important because the environment serves as the context for a person to begin processes related to self and identity. Previous models would have said that African American youth are not interested in higher education and therefore live in economically depressed environments (Spencer, 2006).

Another goal of the PVEST is to examine not only negative outcomes of development but some positive aspects as well (Spencer, 2006). For example, the coping skills that African American youth have developed when dealing with their environments are different than the coping mechanisms of European American youth. This has been viewed as a deficit by many (Spencer, 2006). Spencer argues that the two sets of outcomes for these individuals are a byproduct of the environments and are both important from a developmental aspect (Spencer, 2006). PVEST takes the stability/instability model of Erikson, adds the role of proximal processes as stated by Bronfenbrenner, and embeds this within a very specific environmental context. As a person changes biologically during adolescence, the timing of different identity processes can be linked to different stages in development (Spencer, 2006). For example, as a person enters mid- to late-adolescence, he begins to think about the future and where he wants to end up (Spencer, 2006); this is similar to the foreclosure and identity achievement stages of Erikson's theory.

PVEST accomplishes conceptualizing a person as the linkage of several ratios that act in a reciprocal manner. Figure 2.3 illustrates this further, where A serves 
as the reciprocal linkage (Spencer, 2006, p.848). The ratios are set up so that the most ideal situation is where a person has ratios that are always less than one. The greater the denominator, or number of positive experiences, the more capacity there is to absorb negative experiences in the numerator. A person through their interactions with their environment is exposed to a set of risks and protective factors. This determines how vulnerable they will be to risks overall (Spencer, 2006). The more protective factors a person has, the more risk they can deal with: the larger a person's support system the less their net stress will be (Spencer, 2006) and so forth. Spencer (2006) argues that the types of environmental experiences that African American youth are exposed to are different when compared to their European American counterparts, giving rise to a different set of ways of dealing with complex situations. This is not necessarily good or bad; it just is.

While none of these theories are complete on their own, when combined they provide a flexible framework with which to begin to understand the identity development of Black gay males.

\subsection{Specific Identity Theories}

Concurrently, some researchers were interested in how specific groups developed their identities. Using some of the general theories as a scaffold, the nuances between ethnic, sexual, and gender identity were developed and tested. A review by Frable (1997) examines some of the more popular theories for these specific identities. 


\subsubsection{Ethnic Identity}

In regards to ethnic identity, Frable (1997) states "the child development literature is now characterized by an insistence that the racial and ethnic identities of non-white children be understood in their own terms. Within-group differences are particularly important; when measured, white children's responses are no longer treated as the standard from which responses of others deviate" (pg. 147). Previous models examining how Black children developed did not take into consideration the different types of environments that Black children exist in, be it middle class, urban, etc. Theories of development assumed that all people developed the same regardless of where they were situated (Spencer, 2006).

In 1971, Cross Jr. introduced the theory of Nigrescence, or the process of being socialized into an Afrocentric ethnic identity (Cross Jr., 1991; Frable, 1997). Cross Jr. presents a stage theory using Erikson's model of identity development as the foundation. A person starts out in the pre-encounter phase (Cross Jr., 1991). During this stage a person may not identify with being Black and may believe that "notions of beauty and art are derived from a white and decidedly Western Aesthetic" (Cross Jr., 1991, pg. 191). The main facet of this stage is the outright rejection of anything Black and the acceptance of all things considered to be "White" (Cross Jr., 1991). Over time, a person will begin to aggregate experiences that nip away at the veneer of not having an Afrocentric ethnic identity. When these experiences become too great, the person is said to have entered into the encounter stage (Cross Jr., 1991). 
Having recognized that they are in fact different from the White community they are situated in, a Black person then begins to immerse themselves in all things "Black" (Cross Jr., 1991) and eventually emerges as a newly informed Afrocentric resourced person. Immersion is not limited to participating in stereotypical activities, such as listening to rap music and eating soul food regularly, to consuming black literature and attending events geared towards the extreme ends of the Black community. As time goes on, most people become moderate and filter out what they have learned from their extremist Black experimentation and adopt a more functional standpoint. At this point they have emerged from their Black consumption phase (Cross Jr., 1991).

As with Erikson's stage theories, once a person has begun down a pathway and established the end goal, they must now integrate the newly found information into their current self. Cross Jr. calls this the internalization stage. This stage allows a person to personally define who they are as a Black person using the newly learned terminology combined with the environmental context they exist in. The main functions of internalization include:

1. to defend that person from the negative psychological stress that results from having to live in a society that at times can be very racist;

2. to provide a sense of purpose, meaning, and affiliation; and

3. to provide psychological mechanisms that facilitate social intercourse with people, cultures, and human situations outside the boundaries of Blackness (Cross Jr., 1991, pg. 215) 
The main goals of the internalization phase are similar to the previously stated functions of an identity. Most people stop here in their development and do not necessarily move to the last stage. Commitment is the last stage and is marked by the cognitive commitment to being Afrocentric (Cross Jr., 1991). The main issues with this final stage are the varying definitions of what it means to be committed to an Afrocentric identity. Some persons feel that redefining themselves is enough (or any other stage for that matter) and only progress through a few of the stages (Cross Jr., 1991).

As stated previously, the purpose of the ethnic identity process is to find stability with how a person views himself in terms of his chosen racial and ethnic definition. While it may be believed that a racial or ethnic characterization is ascribed to a person at birth, the process of a person identifying with that label does not begin until much later in life; it usually begins with the first time a person experiences racism (Cross Jr., 1991; Helms, 1990). The point of making meaning of how racism affects a person does not begin until adolescence as the body changes to allow for more complex thought processes and physically matures a person into adulthood (Spencer \& Markstrom-Adams, 1990).

The latest version of Cross Jr.'s theory takes into account the within-group differences inside the black community. A different interpretation based on the Nigrescence model is presented by Helms. Helms (1990) suggests the following modification:

Personal identity (PI) concerns one's feelings and attitudes about oneself, in other words, generic personality characteristics such as anxiety, self-esteem, and so on. Reference-group orientation (RGO) is reflected 
in such things as value systems, organizational memberships, ideologies, and so on. Ascribed identity (AI) pertains to the individual's deliberate affiliation or commitment to a particular racial group. Typically one can choose to commit to one of four categories if one is Black or White: Blacks primarily, Whites primarily, neither, or both. Hence a person who considers one race or the other to be the important definer of Self has a mono-racial ascribed identity; a person who feels a connectedness to both racial groups has a bi-racial ascribed identity; and the person who commits to neither group has a marginal ascribed identity (pg. 5).

Therefore, a person is tasked with balancing the tension between their PI, RGO,

AI. As a person navigates through life, tension will arise between these three components. To resolve or relieve this tension, Helms relies on Leon Festinger's theory of cognitive dissonance (1990):

Festinger proposed three ways of reducing dissonance: (a) changing a behavior, (b) changing an environmental belief, and (c) developing new beliefs. Accordingly, the person in the Disintegration stage might reduce discomfort by (a) avoiding further contact with Blacks (changing a behavior), (b) attempting to convince significant others in her or his environment that Blacks are not so inferior (changing an environmental belief), or (c) seeking information from Blacks and Whites to the effect that either racism is not the White person's fault or does not really exist (adding new beliefs). Additionally, as a means of avoiding an increase in dissonance, the person may selectively attend only to information that gives him or her greater confidence in the new beliefs and/or he or she will interact only with those that can be counted on to support the new belief (pg. 59).

\subsubsection{Sexual Identity}

Katchadourian takes a bio-social approach to understanding how sexual identity is developed beginning with the onset of puberty. Puberty is the primary point 
where secondary sex characteristics begin to develop, priming many adolescents to begin to consider exploring sexual relationships with their peers. Katchadourian (1980) argues "that the profound changes in puberty somehow influence the sexual [both gender and sexual] motivation of the adolescent and that such influence operates in a psychosocial context, which also determines how the adolescent behaves sexually" (pg. 20). A key component of developing a sexual identity is the ability to have sex with a wide variety of partners to determine what fits for a particular person (Katchadourian, 1980).

Frable reviews several stage theories relevant to sexual identity. The two that will be discussed here are the Cass (1979) theory of homosexual identity development and the Troiden (1979) application of the Cass theory. The Cass model follows a similar framework to Erikson's theory of identity development but allows for persons to end the process of developing an identity at any of the stages. Cass (1979) bases this theory by stating that a person proceeds through the stages as a result of coming into contact with objects within their environment. "Growth occurs when [a person] attempts to resolve the inconsistency between perception of self and others" (Cass, 1979, pg. 220).

Cass's theory is divided into six stages: identity confusion, identity comparison, identity tolerance, identity acceptance, identity pride, identity synthesis (1979). The identity confusion stage begins when a person recognizes that his behaviors and desires are different from those accepted by the larger dominant culture (Cass, 1979, pg. 222). This is not limited to only being attracted to the same biological sex but extends to being attracted to both sexes (i.e., bisexual) and to being attracted 
to neither sex (asexual). Cass makes the distinction that "simply to encounter information on homosexuality (even where others label a person's behavior as homosexual) is not enough to begin the homosexual process" (Cass, 1979, pg. 222). The person must believe that his sexual behaviors are not desirable in the context of a heterosexually dominant society. Or stated differently, a person must believe that being non-heterosexual is not acceptable within the particular environment that he lives. A person can then begin the process of resolving the internal tension or ignore it altogether (Cass, 1979, pg. 222).

Next, a person enters into a stage of self redefinition, whereby a person juggles between his current identity and his non-normative sexual behavior (Cass, 1979). This stage can be particularly difficult for people as they isolate themselves from others in the absence of appropriate supports as they redefine their self (Cass, 1979). As with any identity that has not reached a point of stability, a person may avoid situations where he has disclose behaviors or self-concepts that are inconsistent with the world around him (Cass, 1979, pg. 225). Next, a person enters into the identity tolerance phase whereby he actively seeks out people with the final stable identity they wish to develop (Cass, 1979, pg. 229). After building up a new support network, a person then accepts his identity by increasing the frequency of contacts with those with similar identities (Cass, 1979, pg. 231). As his new sexual identity becomes more acceptable at the person level, some individuals begin to denounce heterosexual ideas and values and become an activist for their sexual identity (Cass, 1979, pg. 233). The last stage is identity synthesis (Cass, 1979). This stage involves the reintegration of identities to create a cohesive 
self by re-evaluating where he was from the beginning and adjusting their identity so that is more consistent with the development that has occurred over time (Cass, 1979). A person may discard some of the things he observed during the other sexual identity stages.

The Troiden (1979) model is a similar stage-type model that looks at experiences in relation to normal meaning-making processes during adolescence. The model has four stages: sensitization, dissociation and signification, coming out, and commitment (Troiden, 1979). The sensitization stage occurs around age 13-17 and is where a person recognizes that he is different from his peers, and he begin to seek out experiences to help explore the different urges and desires (Troiden, 1979). The sensitization stage is not limited to homosexual men but is also found in heterosexual men (Troiden, 1979). Next, a person begins to dissociate the experiences he has had with same-sex partners and establish a sexual identity that discretely separates his behaviors from how he views himself (Troiden, 1979). For those who do begin to identify as homosexual, they begin the process of coming out (typically age 19-21) by immersing themselves in the gay community and surrounding themselves with peers who have the sexual identity they desire (Troiden, 1979, pg. 367). Troiden states that after about two and a half years, a person is committed to his homosexual identities and begins to have same-sex and/or opposite-sexed partners as a way to legitimize his identity. A key finding from the Troiden model is that becoming a homosexual is not inevitable based on observed stereotypical traits (e.g. effeminate behavior, being shy, etc.) nor is it related to engagement in stereotypically opposite gender activities (e.g. sewing, cooking, etc) (1979, pg. 
$372)$.

\subsubsection{Gender Identity}

The creation of a gender identity is directly related to biology: how one conceptualizes gender is related to how one's body develops and the expectations society places on that form (Bem, 1993; Frable, 1997; Herdt, 1990). Therefore, the development of a gender identity is the reconciliation of the biological changes to a person balanced with the expectation of the form that a body takes. Kohlberg (1966) argues that how a person develops his gender identity begins early in life. A child most often selects a gender that is consistent with his biological sex and begins a process of making value judgements based on the environment he is situated. As a child gets older, he identifies with his same-sexed parent and begins to emulate that which has been observed in relation to identity and sex-roles, e.g. father, provider, etc. With the onset of puberty, the changes that a person goes through are relatively fixed.

\subsection{Intersections and Shortcomings of Existing Theories}

None of the theories present thus far has been able to fully capture the possibly unique intersections between being an ethnic minority and a sexual minority. For the purpose of this thesis, the intersection between being male, homosexually identified (gay, bisexual, asexual), and Black/African American/Mixed Ethnicity are considered. Some studies have attempted to apply portions of these theories to capture the unique experiences of this group. A study by Poteat et al. (2009) examined the intersection between being a sexual minority and an ethnic minority 
for men and women. The researchers hypothesized that youth who identified as Black gay males would report more "psychosocial concerns" than White gay males (Poteat et al., 2009, pg. 197). This finding is consistent with research by Consolacion, Russell \& Sue (2004) who also reported that both "African American and White same-sex attracted youths reported more suicidal thoughts" (pg. 209). This is based on a hypothesis that being a part of multiple minority groups compounded the number of stressors that a person encountered when developing. Consolacion et al. does offer the caveat to their findings: "The findings show that sexual minority status does not necessarily predict compromised mental health and that various patterns on mental health measures emerge when different racial/ethnic groups are examined separately" (Consolacion et al., 2004, pg. 211).

Several researchers suggest that there are no differences in developmental milestone achievement (i.e. age of realization, age of experimentation, etc.) between ethnic and white populations (Jamil et al., 2009; Rosario et al., 2004; SavinWilliams, 1998). It is hypothesized that male African American adolescents go through a different set of proximal processes when developing their sexual and ethnic identities than white heterosexual males. Research findings by Rosario et al. suggest that ethnic minority youths "experienced the developmental milestones of identity formation around the same time in their lives" when compared to other youths (Rosario et al., 2004, p. 225). Further, the development of an ethnic and sexual identity happens simultaneously but their dependence on one another is not well known (Rosario et al., 2004). Jamil et al. did conclude that the development of ethnic and sexual identities were two separate but simultaneous processes (Jamil 
et al., 2009, pg. 210). Rosario et al. did not find any connection between the forming of sexual identities and one's cultural identity (2004). While ethnic minorities had similar sexual developmental processes as their majority peers, they were less likely to be involved in Lesbian, Gay, Bisexual, Transgender, or Queer (LGBTQ) focused groups or participate in LGBTQ community activities. Ethnic minorities had similar rates of identifying or engaging in same-sex activities as the majority sample. This finding, however, is limited to the sample that was obtained by Rosario et al.. A more accurate appraisal of identity formation at this intersection would best be investigated with a longitudinal study where the participants are followed during their entire progression through adolescence (Rosario et al., 2004).

African American men are more likely to explore their sexual identity in private and will often delay labeling their sexual behavior (Dubé \& Savin-Williams, 1999; Jamil et al., 2009; Poteat et al., 2009; Rosario et al., 2004; Savin-Williams, 1998, 2001). Additionally, some populations of African American men may feel more inclined to identify and engage in heterosexual behaviors and/or relationships to prevent overt conflict with their ethnic and gender identities. A person's ethnic identity, therefore, could play a more salient role for men when exploring sexual identity.

Ethnic identity development tended to be a public, external process, drawing from resources in the larger community while sexual identity tended to be more of a private, internal process with limited access to resources (Jamil et al., 2009, pg. 210). The findings from the Jamil et al. study are limited in scope because the interview script used to examine identity did not consider developmental factors 
(Jamil et al., 2009, pg. 212). The sample was also drawn from a local LGBTQ center that specialized in providing resources to sexual minorities, suggesting that the findings may not be applicable to the larger population (Jamil et al., 2009, pg. 212).

Other studies have been conducted examining developmental risks (i.e. depression, suicide, drug usage, etc.) of people within this particular population (Consolacion et al., 2004; Dubé \& Savin-Williams, 1999; Jamil et al., 2009; Poteat et al., 2009; Savin-Williams, 1994, 2001). However, all of these studies recognize the need for diverse and more representative samples to fully understand the possibly complex interactions of these identities.

\subsection{Dynamic Systems Theory}

All of the theories reviewed so far are attempting to reconcile the tension created between stable and unstable states. This tension may come from attributes that are assumed about one's gender from biological development or the reconciliation of racist experiences confronted from the dominant culture. Dynamic systems theory is a tool that can be used to understand how a system goes from stable to unstable to stable states (Diamond, 2007; Thelen, 2005; Thelen \& Smith, 1998; van Geert, 2003; van Geert \& Steenbeek, 2005). Thelen (2005) argues that the dynamic systems approach to development should be used because it takes into consideration both underlying processes and their associated outcomes. As researchers begin to identify the complexity of the developmental processes, new 
methods must be created and modified to account for the contributions to a person from their environment, biology, and cognitive states. Similar to the previous theories, movement between states requires a period of instability (Thelen, 2005, pg. 294). To reach a new stable state requires input from different processes either inherent to the person or from the environment that a person is situated (Thelen, 2005, pg. 265).

Thelen uses dynamic systems theories to examine how children make sense of the world from birth to about age three and states:

I see development as this process of assembling patterns of behavior to meet demands of the task in the biological possibilities of the child at that time. Sometimes the behaviors are stable for a time-they are easily elicited and frequently performed. Then other behaviors emerge, and the old ones become less available or less preferred. In this sense, children are always problem solving, using what they have to perform actions that are intrinsically rewarding or pleasurable for them. Development is thus the product of the child's everyday and continual efforts to make things happen in the world (Thelen, 2005, pg. 263).

Without dynamic systems theory it may not have been possible to conceptualize the development of children in non-linear ways. Diamond (2007), in the study of identity development of lesbian women, used dynamic systems theories to see how different "control parameters includ[ing] biological predispositions, early sexual experiences, sex drive, cultural norms, opportunities for same-sex versus other-sex contact, and so on" (pg. 155) influenced how lesbians viewed themselves over time. Over time, how a person viewed herself often changed as a function of the availability of certain partners or negative experiences with persons of the same or opposite sex (Diamond, 2007). 
The previous two authors expressed how dynamic systems thinking could be used to explain changes in states. A different perspective is offered by van Geert \& Steenbeek that stresses the importance of being able to impose a physics-like model on development (van Geert, 2003; van Geert \& Steenbeek, 2005) . van Geert \& Steenbeek's model of development states that

$$
y_{t+1}=F(y t)
$$

where $t$ is time, $y$ represents the state a person is in, $F$ is the function that is going to modify the person, and $t+1$ represents the next state. Thus, a person occupies some state at $y(t)$. A $F$ causes the state to change over time $y_{t+1}$. These changes between states can be plotted and an equation of fit can be applied to represent the pathway to a particular outcome. Comparisons can be made between people with similar developmental outcomes and/or pathways. Ultimately, this allows researchers the possibility to attenuate inputs and processes which then allows for them to make statistical predictions on a range of possible outcomes. Dynamic systems also takes into consideration that there are an infinite number of pathways that can be taken to get to a particular outcome and that one is no greater than the other.

Dynamic systems theory is therefore the best framework to use to organize initial and final states, overall outcomes, and the processes that influence the changes in states. The primary limitation to this methodology is that no existing framework or method exists to deploy this methodology (Diamond, 2007; van Geert, 2003; van Geert \& Steenbeek, 2005). Another limitation is that this way of thinking requires intense knowledge of mathematics and physics-based models, which may be 
difficult for researchers who are unfamiliar or uncomfortable with mathematically intensive models (van Geert, 2003; van Geert \& Steenbeek, 2005). 


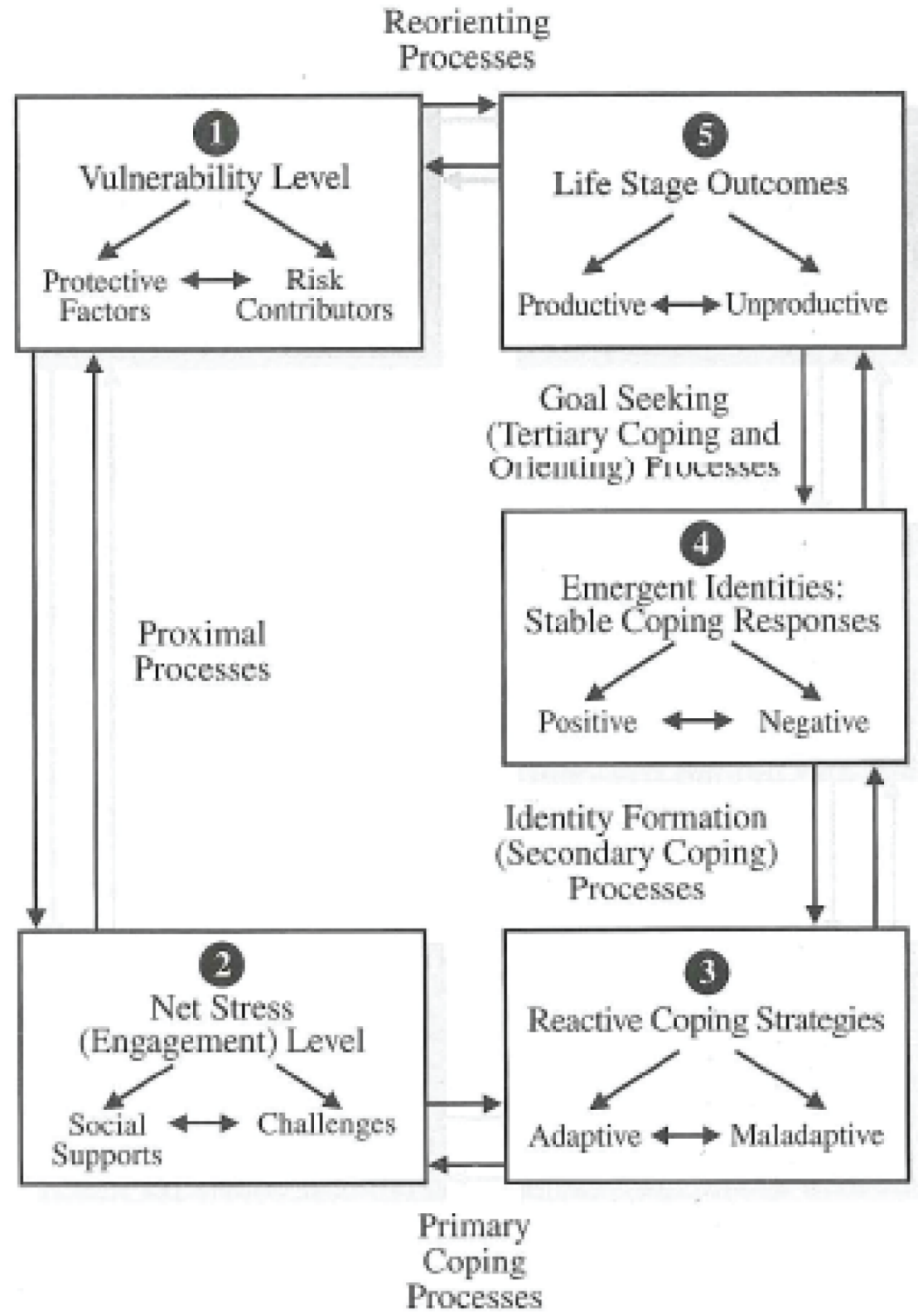

Figure 15.20 Processes Emphasizing Phenomenological Variant of Ecological Systems Theory (PVEST). Source: From Spencer \& Harpalani, 2004.

Figure 2.3: Taken out of Spencer paper (Spencer, 2006, pg.886) 


\section{Chapter 3}

Pilot Study

\subsection{Pilot Study Description}

A pilot study was conducted as a part of the course Applied Developmental Psychology taught at Portland State University in Portland, Oregon. A small research project was conceived and completed that consisted of five interviews of adolescent gay black males. The goal of the study was to explore and identify the specific processes that adolescent gay black males go through when forming an intersected identity. The particular intersection of interest was where one's ethnic/racial identity meets one's sexual minority identity. The scope of the smaller study excluded gender as a participatory identity; while gender does play a direct role in how both sexual and ethnic identities are formed; it only served to further complicate the analysis in the project. The main organizing framework used was Bronfenbrenner's proximal processes as the main theoretical backbone. Interviews were conducted by recruiting persons from local LGBTQ centers and by using a snowball technique. A snowball technique works by asking a participant if they personally know of anyone that fits the participant description and then recruiting them to participate. 


\begin{tabular}{ccclcl}
\hline & & \multicolumn{3}{c}{ Identity } & \\
\cline { 3 - 4 } Name & Age & Gender & Ethnic & Sexual & Education \\
\hline Jay & 21 & Male & Black & Gay & In College \\
Rory & 26 & Male & Puerto Rican & "Sexual" & In College \\
Jessie & 24 & Male & Afr. Amer. & Gay & Master's \\
& & & & & Degree \\
Chris & 24 & Male & Black & Gay & In College \\
Skyler & 24 & Male & Black Amer. & Queer & In College \\
\hline
\end{tabular}

Table 3.1: Summary of participants and their respective demographics from the pilot study. Pseudonyms were used to protect the person's real identity.

\subsection{Methods}

Understanding where the respondents are in their lives as well as where they currently live provided some context to some of the responses that the respondents gave during the interviews. The participants ranged in age from 21 to 26 and all self-identified as male. Interviews were conducted in one session and ranged in length from 34 minutes to 108 minutes. Interviews were generally conducted in the evenings with one being conducted in mid-morning. Most of the interviews were conducted in person except for two interviews that were conducted using Skype ${ }^{\circledR}$. A summary of basic demographics of participants is presented in Table 3.1. Signed consent was obtained from all participants prior to interviews being conducted.

Respondents were interviewed using a modified version of the MOSAIC scale developed at DePaul University (Jamil, 2010; Jamil et al., 2009). The questions consisted of a general narrative statement, followed by questions pertaining to each person's individual ethnic and sexual identities. Respondents were then asked a 
series of questions about how their identities intersected (if they did), the process they went/are going through, and what (persons, books, groups, etc.) informed them during this process. The last section of the interview involved a Context Identity Saliency Questionnaire (CISQ): a context would be named (e.g. a room of all white identified people) and the respondent stated which of their identities was most salient as they navigated that context. The goal was to determine if respondents reported a more integrated identity that included both ethnicity and sexuality in the given context or if they selected one of their individual identities. The script was later modified to ask questions about a person's gender and not assume one's gender based on presentation alone. A copy of the modified MOSAIC scale and the CISQ are included in the appendices. A copy of the survey instrument is included in Appendix A.

Primary comparisons were made between those who had developed a cohesive individual identity, both ethnic and sexual, and those who had not. Cohesiveness was initially assumed to be the use of one overarching identity to interface with different communities and contexts. Their two identities, developed independent of one another would intersect and a new identity would emerge using components from both identities. Figure 3.2 illustrates how this hypothesis of development would occur. The contrast of interest was between males who had developed an intersected identity with those that had not fully developed an intersected identity. It was hypothesized that

- having an intersected identity was important to developing adolescents, and

- this was only possible after one's sexual and ethnic identity were constructed. 


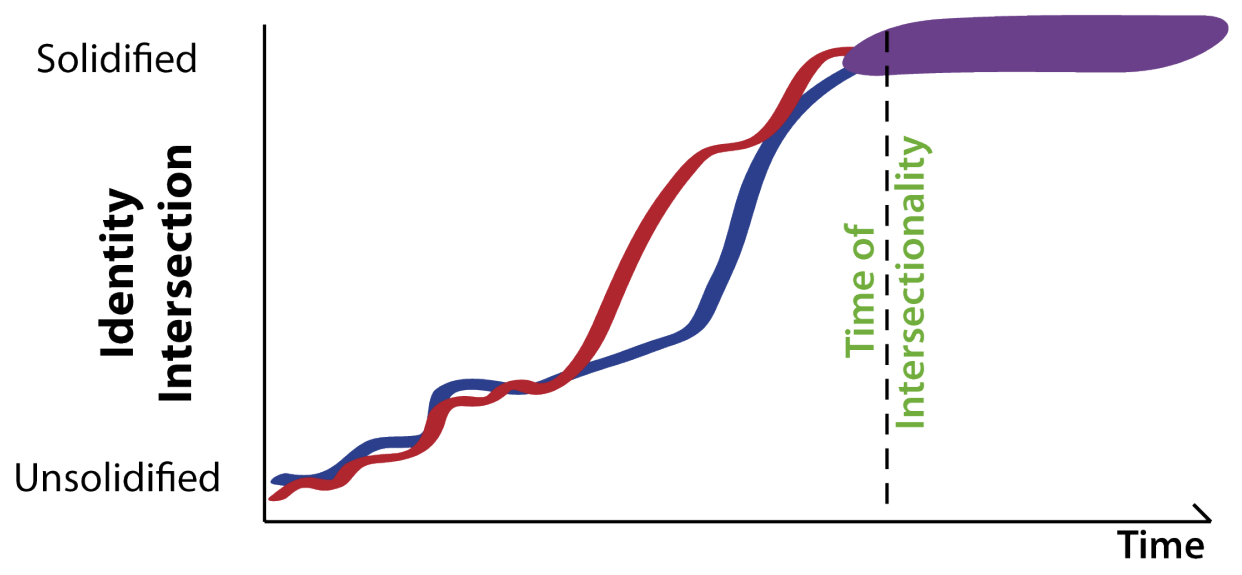

Figure 3.1: Illustration of the hypothesis regarding the two individual identities intersecting at some time and creating an intersected identity. The thickness of the line denotes differences in proximal processes of a person. The line shows the progression from unsolidified to solidified identity.

The proximal processes were expected to differ mainly surrounding the intersection of a person's identities. It was predicted that persons with a more intersected identity would

- not deny who they were in different contexts

- would worry less about how others perceived them, and

- would also be more likely to help out other ethnic-sexual minorities during their development.

\subsection{Results and Analysis}

Subsequent analysis of the interviews revealed that one's ethnic identity was more salient than their other identities based on different presented environmental 
contexts. Many respondents reported that it is difficult to hide their ethnicity since it is immediately observable when walking into a room. Respondents also reported seeking out community support from individuals or organizations that shared their same ethnicity. However, respondents also reported that there were a lack of organizations for ethnic sexual minorities. Lastly, many individuals did not feel that they were in a safe enough environment to intersect their identities and therefore did not know what it would be like to exist as an ethnic and sexual minority. For the most part, the respondents had learned to keep their identities separate. Figure 3.3 illustrates these findings.

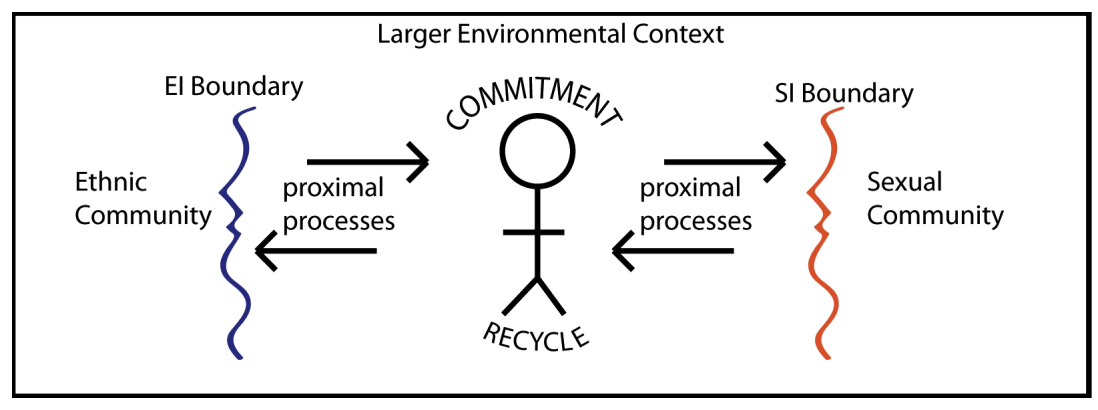

Figure 3.2: Illustration of the final model that was used to conceptualize the different developmental pathways. EI stands for ethnic identity and SI stands for sexual identity. From the interviews, the ethnic identity was generally more developed and prioritized as more important than one's sexual identity. However, the respondents were also more excited to discuss their sexual identities than their ethnic identities.

The interview with Chris will be contrasted with Jay, Rory, and Skyler. Jessie will be used in the contrast of integrated identities even though he does not feel the need to have an integrated identity since he does not exist in a context that he believes requires one. 
For all of the respondents, when asked about which identity was more salient in an all-white context, all remarked that their respective ethnic identities were more salient than the others. Similarly, Chris and Jessie responded almost the same way when placed in the other contexts. When reviewing the processes that these two individuals went through, we find that the previously listed proximal processes were present: Chris did not deny who he was in different contexts; he did not worry much about how he was perceived by others in different contexts; he was also willing to help others in their development. When asked about the process of intersecting his identities and whether there was tension, Chris stated that while there was tension, he was willing to put up with this because he knew it would ultimately make him a better person in the long run. Residing on the east coast and working with different activist organizations, he recognizes that he must be capable of standing his own ground when dealing with people of different backgrounds, regardless of how they viewed themselves. What was particularly interesting was Chris, when asked which identity was most salient if he was in a room of all possible sexual identities, he responded white. This for me raises several questions: how flexible is he in his other identities that allows him to identify this way? Is he merely aligning himself with more of the white ideas and processes of being gay? Many of the other respondents also said that the gay community felt very white, which made them feel even more like an outsider.

Jessie, while responding very similarly to Chris on the CISQ, had a different pool of resources to develop his (un)-integrated identity. He says that he is involved in a fraternity that is made of all gay and black members. These members provide 
the social partners necessary to allow the existence of proximal processes for development. In regards to the proximal processes listed above, Jessie felt that who he was as an individual was far more important than either identity, but it took the support of his peers in order for him to reach that point. And while his overtness about who he was as a black, gay male did not deter him from bringing that to everyone's attention, he had enough support to be able to fight discrimination and stereotypes that were presented to him in return. His only wish was that there were more resources in the form of black, gay males who could help others find their way. I would argue that the existence of these role models hinges directly on the context that one exists in.

For others, it may be more important to independently develop their respective identities. This was particularly true for Rory, who stated that even though his two identities define who he is, it is not possible to intersect these two identities because he does not exist in a safe enough context to intersect them. He does not have enough of a Puerto Rican community to support him at all; this means that he definitely does not have any gay or queer Puerto Ricans to poll if he were in need of help through that phase. Subsequently, he does not feel safe enough to "come out" in his community for fear of retribution. It is as if he walks around juggling two balls, unable to catch one for fear of losing the other. Rory also states that he lacks the language to fully illustrate his experience to others. That, combined with the lack of resources available to him, makes him hesitant to begin to integrate his identities. He argues that he does a lot of anti-racism work in the community, but it is mainly with English-speaking persons; if he could find other 
transmale, Puerto Rican, queer/polyamorous people then he would be more likely to begin the process of integration. In that regard, the process of developing an integrated identity is not here because Rory does not have a socializing group to have proximal process exchanges with.

The most promising view of intersectionality was from Jay, who recognized that the tension that he experienced at the intersection of his two identities was something that he should conquer. What was interesting was that the process of resolving that intersection hinged on acceptance within the gay community and not necessarily the black community. This would suggest that the gay community would then serve as his main socializing group; his proximal processes focused on learning, adapting, and exploring what it means to be gay. Jay stated that he never felt accepted by the black community; in committing to and recycling his gay identity though, he recognized that he needed black social partners in order to fully develop both identities to their optimum levels. I would hypothesize that as Jay's black identity becomes more developed, his views on the intersection of his black and gay identities will change.

There are feedback loops present in each of the narratives collected. These loops are best summarized by Chris who said,

Chris: It was basically a lot of trial and error. And I think first I have to sort of disband my own prejudices. I admittedly have prejudices or assumptions about white people that I have to work on and I have uh prejudices and assumptions about certain types of gay people that I need to work on.

That quote summarizes the entire process of developing the independent identities, finding the appropriate context for development, engaging in proximal processes, 
committing to an identity, then recycling back through this process as contexts change over time. This process continues until some sort of stability is reached. While this process sounds somewhat mechanistic, I would argue that it is dialectally contextual since the engine changes as a function of the context that it is situated in. Figure 3.3 illustrates this concept based on these findings.

Other developmental contexts or persons that were not specifically mentioned in regards to developing one's integrated identity included the internet, academia, a person's respective ethnic or sexual community, and white queer Pacific Northwesterners. Future studies should examine how sexual ethnic minorities find language to describe their experiences, the time and effort it takes to educate therapists of their unique position, time spent researching about others like themselves, and the role of pornography in developing a healthy identity.

\subsection{Strengths and Limitations}

One of the greatest strengths of this pilot study is that I was able to sample and describe specific developmental processes of a group that is often ignored by society and by psychologists in the past. This strength is simultaneously a limitation because the findings from this study are limited to specific populations that have similar qualities to those that participated. Nonetheless, understanding the specific challenges this group faces may give researchers that deal with dominant populations, ideas on how to design programs that take into consideration the full breadth of the human experience. Another strength of this pilot study was the open-ended style of collecting data: respondents were allowed to tell as 
little or as much as they wanted about each question, in a safe, relatively low-risk environment.

In addition to the previously mentioned limitation, the amount of data collected from each participant makes it difficult to find parallels across all participants; the best that could be done was to generate themes of identity development and group the responses based on these themes. A large sample size would help narrow down how to shape these themes, but even the small sample size introduced a vast amount of variability in responses. Another limitation of the study is that no follow-up was scheduled to observe a change in state currently. Participants in a research project like this should be interviewed at different time points to see how they have changed in regard to their main identities and their intersected identities. This would also illustrate if people change their main socializing contexts over time.

While the interview questions used in this project were good at drawing out the different themes, the questions should not be used for future research. The questions allowed me to probe into messages and communities but many of the processes had to be inferred from how the person identified with the messages and communities. In making these inferences, the interpretation of the inference is in the eye of the interviewer and not necessarily in the words of the interviewee. Future iterations of this study should involve more questions about processes as well as the role gender plays in the development of sexual and racial/ethnic identities. For the scope of this project, gender was removed because it introduces an additional layer of interpretation that could have made it more difficult to interpret the results of interest. Many of the interviewees brought up gender in their responses, 
which suggests that the role of gender may be more influential during this process than previously believed.

A final critique of this project was whether the intersection of identities is even necessary. I would argue that it is important to have developed identities independent of one another; an intersected identity may only be useful for those who occupy unique contexts where being multifaceted is necessary. For example, do intersections help gay black men that also live in all gay or all black environments. Perhaps the tension that exists at the intersection points is there because the identities are not necessarily supposed to mix. Future research should look at this concept in greater depth. 
Phase I: Unintegrated
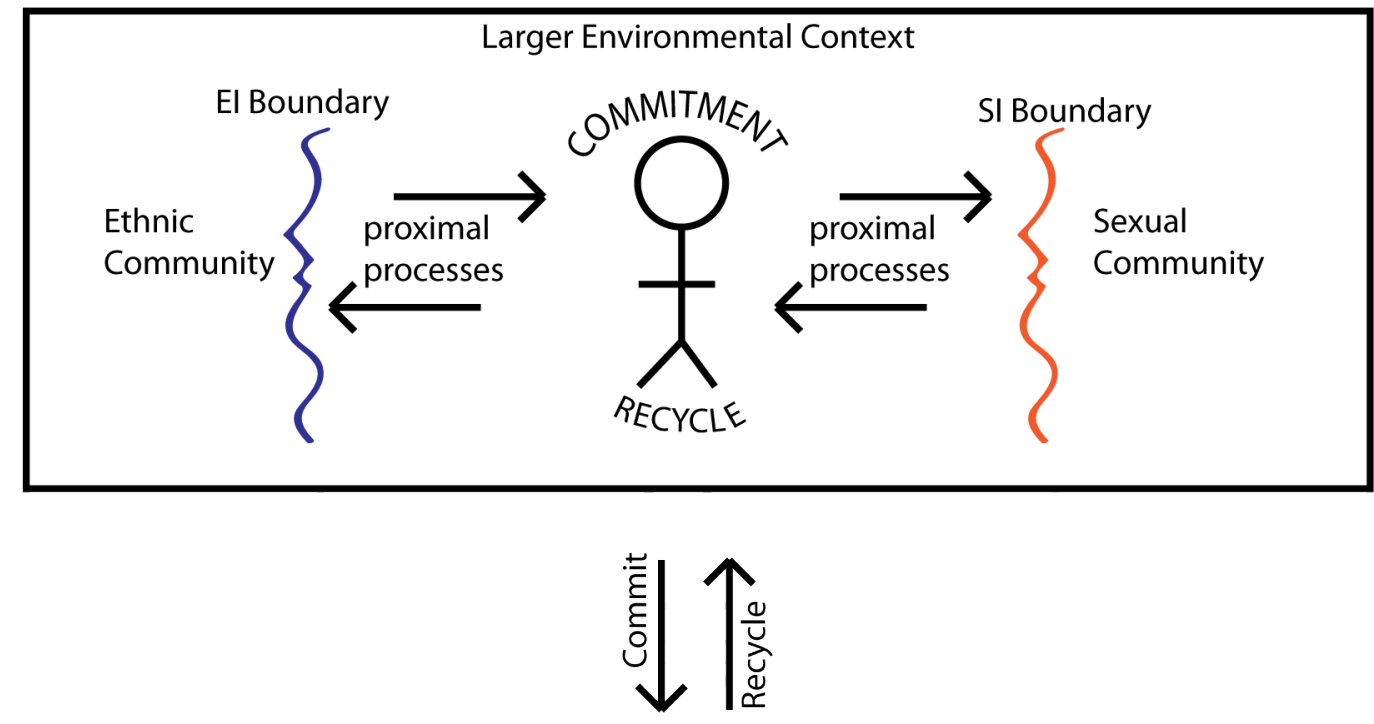

Phase II: Integrated

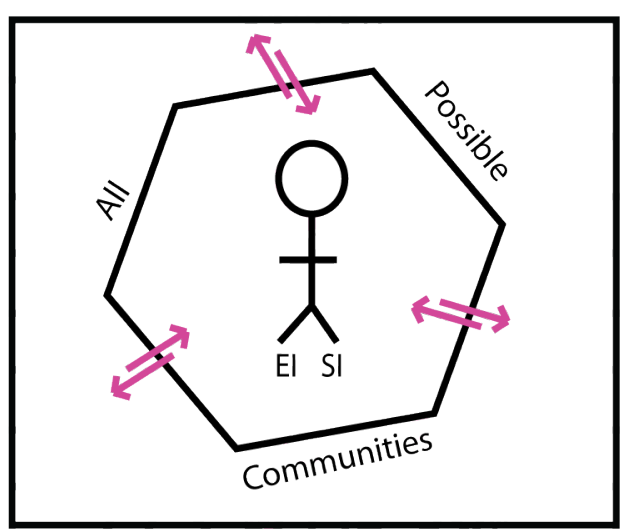

Larger Environmental Context

Figure 3.3: Illustration of the final model used to conceptualize the different developmental pathways. It was determined that the idea of recycling and commitment (or trial and error) was the best framework to help capture these processes. All sexual and ethnic minorities start out at Phase I and slowly work their way to Phase II. It appears from one of the interviews that it is possible to recycle back into Phase I depending on the context that one is currently in. 


\section{Chapter 4}

\section{Part I: Primary Study - Interviews}

\subsection{Interviews}

The primary study expanded ideas from the pilot study but focused more on illuminating the specific developmental processes that adolescents go through to develop their identities. Since an identity functions not only as a buffer but also a lens to look at different environments, it is important to understand the process of developing an identity. Additionally, it is important to examine how different identities, developed and undeveloped, allow adolescents to interface with environments and stressful situations. Spencer proposes a model called the Phenomenological Variant of Ecological Systems Theory or PVEST (2006). The model describes how different factors (environmental, cognitive, biological, etc.) both positive and negative, interact to influence how an individual manages stresses in his environment. These particular developmental outcomes are of interest because the final view of one's identity could influence the limits of their identity. Since identities serve as a buffer and a lens, underdeveloped identities may limit the number of ways that an adolescent can negotiate within different environmental contexts (Dubé \& Savin-Williams, 1999; Jamil et al., 2009; Rosario et al., 2004; Rotheram-Borus \& Langabeer, 2001; Spencer, 2006). 


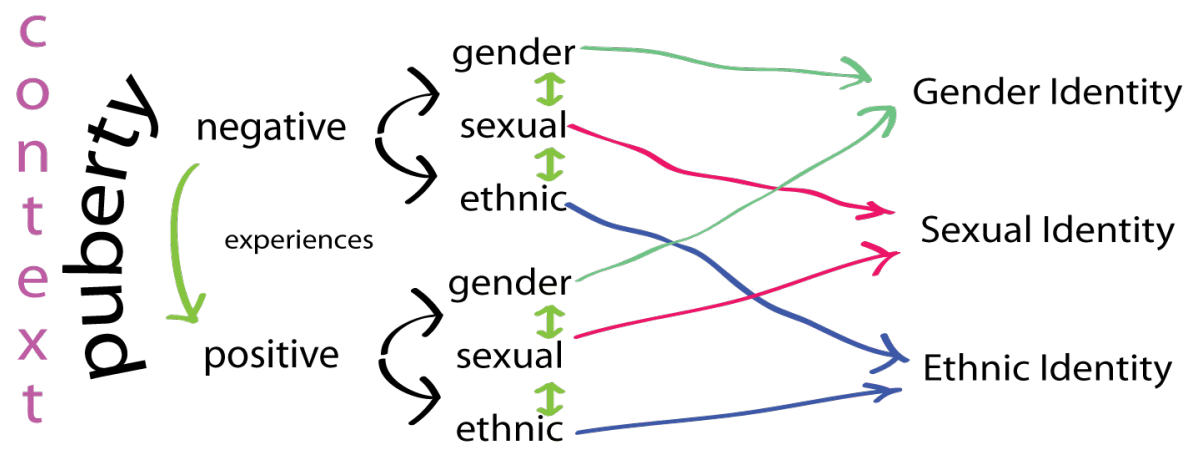

Figure 4.1: Illustration of the PVEST model.

What is most important when applying this model to development are the specific processes and developmental outcomes. While doing comparative analysis of what is considered normative would be illustrative, this study is primarily interested in collecting the processes that an adolescent employs to develop a cohesive identity. Spencer argues that focusing on processes and outcomes discourages deficit thinking that can ultimately undermine how people develop into who they are (2006).

The specific questions of interest for this project are:

1. What processes do male, sexual and ethnic minorities go through as they develop their identities during adolescence? What role does the environment play in developing their identities?

2. Do each of the identities of male, sexual and ethnic minorities intersect with one another? Does the intersection of identities cause internal or external conflict? Do these identities complement each other?

3. What would a dynamic systems model of male, sexual and ethnic identity 
development that incorporates environmental contexts and influences (i.e. peers, other resources), and biological changes during adolescence, look like? Can a dynamic model add clarity to existing knowledge of identity development of male, sexual and ethnic minorities? Can this model be used to generate new theories that allow for a better understanding of developmental processes of male, sexual and ethnic minorities?

A complete outline of the survey instrument is included in Appendix B.

\subsection{Methods}

The focus of the thesis is on the specific processes that adolescents go through when developing their identities, their current "identity" outcome, and the role of the environment during this process. To do this, the MOSAIC interview was modified again from pilot study. The questions were rewritten to focus more on the processes and environments and less on the narrative of the self. The MOSAIC also includes questions about gender and a set of questions where individuals will rank their identities given a set of environmental conditions. Some of the questions include:

1. How do you identify yourself in terms of your gender identity? [GI]

2. How do you identify yourself in terms of your ethnic/racial identity? [EI]

3. How do you identify yourself in terms of your sexual orientation/identity? [SI]

4. In general, what is it like being a [participant age], [EI], [SI] [GI]? Please limit your responses to how each of your identities interact with one another (if they do). 
(a) Do your identities ever come into conflict with one another? If so, how do you mentally resolve some of these conflicts? What external influences help you reconcile this tension?

(b) Do your identities ever help you in ways that having a single identity wouldn't? What external influences help you reconcile these situations?

(c) How important are labels to your identities?

(d) What functions does your total identity narrative serve for you?

\subsection{Participants}

Data for the present study consisted of semi-structured interviews from the pilot study and an additional seven interviews with new participants. All participants identified ethnically as a part of an ethnic minority group. All participants identified as a sexual minority and identified as male. Participants ranged in age from 21 to 28 . All interviews were conducted individually except interviews 10 and 12 , which were conducted concurrently. Interviews were an average of 95 minutes in length and were all conducted in person. Written consent was obtained from all participants prior to interviews being conducted.

Participants were initially recruited from local organizations that provided resources for sexual minorities in Oregon. Organizations were sent hard copies of the flyer with a contact email address. A copy of the flyer can be found in Appendix D. No participants were recruited in this manner. The flyer was then posted on local message boards. One participant was recruited using this manner. The majority of the new participants were collected using a "snowball" technique, where people in the community or current participants are asked to provide names of people 
they know that fit the parameters for participants. After those participants were screened and interviewed, these participants were asked if they knew of others that fit the description parameters. The Human Subjects Review Board at Portland State University was kept abreast of all changes to the original recruitment plan and agreed to the methods used for recruitment of participants. A summary of the participants used is included in Table 4.1 
Part 1: Primary Study - Interviews

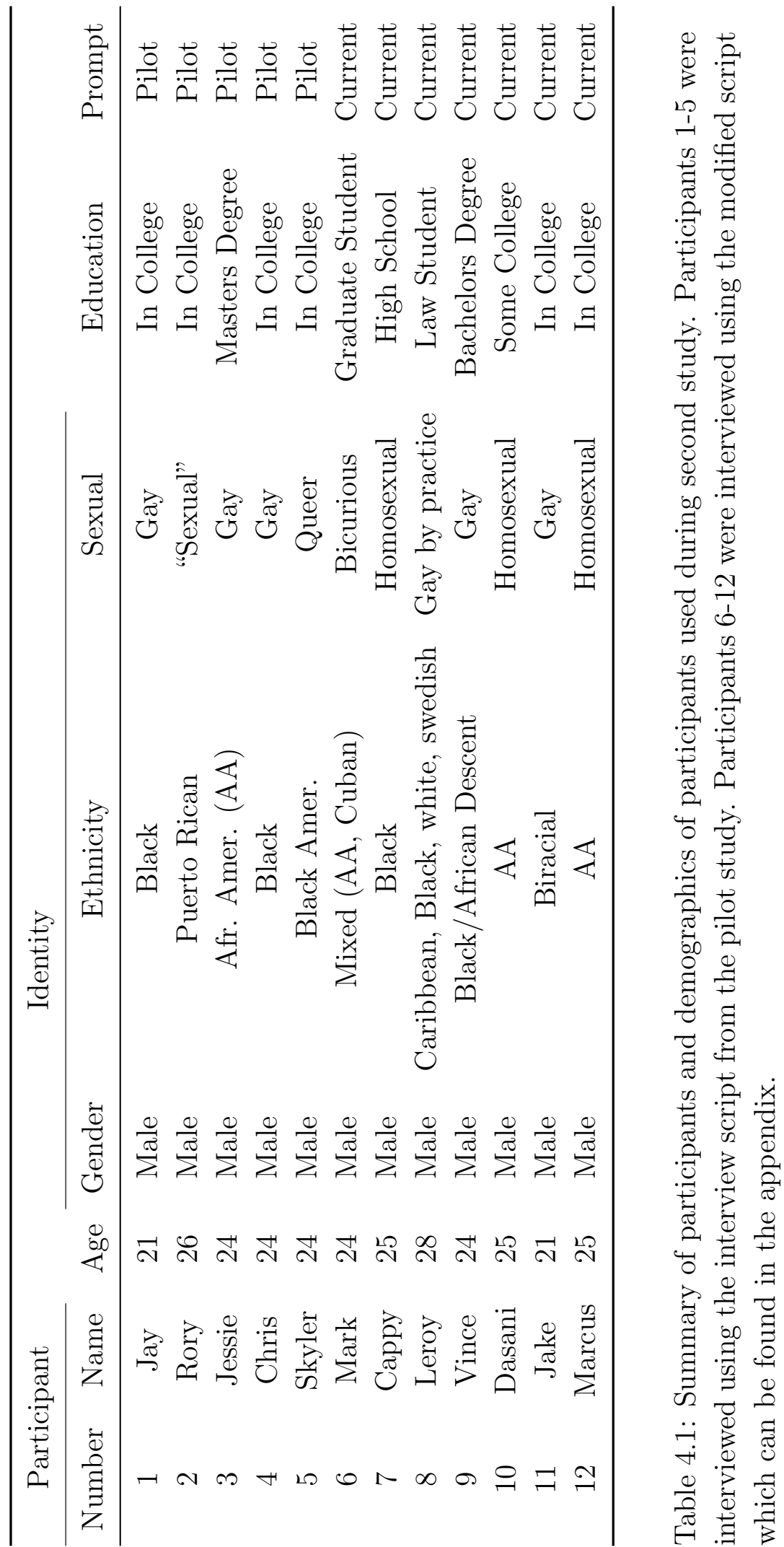




\section{Chapter 5}

\section{Part I: Results - Interviews}

\subsection{Interview Results}

Qualitative interviews were transcribed after the interviews were completed. Time to transcribe an interview varied between two to three hours. Transcripts were formatted using $\mathrm{AT}_{\mathrm{E}} \mathrm{X}$ and formatted into a searchable portable document format (PDF) document. This format is more secure than a standard word document because the transcripts cannot be modified without editing the source file and recompiling the document. After transcription, several questions were reviewed for thematic analysis. A summary of the specific identity themes from the questions are presented. The results from the CISQ are presented next. A combination of data from the CISQ and extracted themes will be used for the model development in Part II of the thesis. Even though Rory did not self-identify as black, his results were included in subsequent analysis because he felt that his experience also reflected those of black Americans. 


\subsection{Specific Themes}

\subsubsection{General Identities}

When asked to describe themselves within the context of their sexual, ethnic, and gender identities, most of the responses indicated that they occupied a particularly unique space. This uniqueness was viewed both positively and negatively. On the positive side, some respondents felt that they could be a resource for others. Dasani described how being gay and African American puts him in a unique position when interacting with others that also allows him to view himself in a more positive light:

I think being black and gay for me puts me in this really unique minority [of] being a minority of a minority. I think it builds a certain character because it naturally comes with certain stressors. And I think I've been afforded a really cool platform to be a leader; and to make an impact I guess and if there was a bigger demand for it; it is something that is a bit of a positive thing to me. But that's what I can't really explain it. Like, I have had many different girls and guys come up to me and just being able to look at me as being out and not being in the same community was a bit of a positive thing for them. And they didn't identify with some of the other people; it was always foreign to them. This person doesn't look like me, this person doesn't grow up in the same neighborhood as me, and it was cool; it put me in the situation where I had to share my story more. And it helped me in hindsight be comfortable with who I am because I spent so much time explaining it.

This uniqueness was also echoed by Mark, who used his African American and male identities to connect with students at his place of employment. Vince felt that the uniqueness made him feel like a jewel that people sought out. Leroy also felt that his identities allow him passage into circles that previously he would have felt unwelcome. The combination of his identities, in that regard, often benefits 
his social mobility.

The positive aspects of being a minority within a minority also comes with some negative components. Many felt that they did not have a community they could readily attach to. Cappy, Vince, and Marcus all felt like an other as they attempted to navigate within different communities. Cappy stated,

I guess it's interesting. I don't necessarily find people who I resound with very nicely as far as other black gay males. I've had black female lesbian friends that have worked out; but as far as me and the rest of the gay black community I don't feel that I mesh all that well. And so it's interesting from that standpoint because I feel like I am on the outside looking in on an entire community. It kind of just doesn't get me even though I am a part of them. As far as the gay community at large, I feel like I am so sort of rarity. A lot of people of different ethnicities say that I am a pretty odd duck as far as gay black guys go. I'm not really too effeminate. I'm definitely not the most macho guy on the planet.

Vince argues that there is discrimination within the gay community which he finds indicative of the present time. He goes on to describe how even the terminology that we use to describe gay people has changed over the last half century. All in all, he concludes by saying "It is an interesting way to be alive. I guess you can sort of say kind of what you make of it. If you put a lot of stock into what people think then you're not going probably not going to have a good life. Today as a gay black man. But if you kind of go on your own way and be careful of the people that you choose to be close to you or whatever it is a lot of fun." 


\subsubsection{Gender Identity}

All of the participants described themselves as being male. Most participants discovered or developed their gender identities at an early age. Some participants felt that their gender was ascribed to them at birth. Others took a more formal approach by questioning their parents or observing the peers around them. For many, their gender identity had a strong influence on how they developed further. Cappy and Jake determined their gender identity was related to physical features: masculine build, having a penis, smelling like a man. The remainder of the group attached their gender identity to being a provider for themselves or for their communities. Self sufficiency was echoed repeatedly as a key attribute of their maleness. For three of the participants, their male identity was developed publicly while for the remaining four it was a private endeavor. Most had male family members who served as significant persons when developing their gender identities except Cappy (Harter, 1990). Cappy found his understanding of his male identity after his first romantic relationship with another male ended. In his words,

Oddly enough, I guess I didn't feel really developed until after I broke up with my first boyfriend. My mom taught all the academic stuff; but even she was willing to admit right off the bat that she didn't know anything about being a guy. She could tell me everything she thought was right; but I didn't really have a male figure that I could look up to. She got remarried when I was 11 but I didn't like her husband and it was because I didn't thinks she really liked him, which I still stand by. He's not a terrible person. He's super lazy. He wants to be a kid forever. Doesn't really like the responsibility of being a dad so he just doesn't. We didn't spend all that much time together. And I didn't really look up to him in a male fashion. Like I never asked him those questions or anything like that it wasn't until I dated my first

long-term boyfriend that I got a sense of what another guy who, you 
know, who could be, like, just, like just like he was just a dude. And I hung out with him and it was cool a lot of the things I do as a guy, as a gay guy, you know. I got from him and so I developed my own sense of self from hanging out and interacting with this guy.

He recognized through interactions with his family that he was a male but what that meant to him did not find meaning until later.

For some, the internet served a key role in developing a cohesive male identity. Mark used the internet to find masculine examples of men as points of reference at his place of employment. Leroy stated that "the internet took over for whatever community I didn't have in the town I grew up in. The internet helped to fill in for what I didn't know and since it was a blank slate. The internet let everything be defined broadly: politics, academia; morals were defined by parents." All of the respondents felt that they fit well within their male identities. The one resounding desire for them was a male role model to look up to or discuss difficulties they were experiencing. There was an observable difference in security of identity between those participants that had male role models (there were two) and those that did not.

\subsubsection{Racial/Ethnic Identity}

The development of an ethnic identity of respondents was observed to begin in elementary school as they began to notice that they were different from their peers. Some recounted experiences of overt racism; others were curious as to why their skin was darker than others. The common understanding amongst participants was that their racial and/or ethnic identity helped them interact with others with

similar features as themselves. It also gave themselves some type of common 
historical and cultural relevance in relation to others. Two respondents, Cappy and Leroy, felt that having a racial and/or ethnic identity was quite repulsive. Cappy states,

... but being black to me is having to add another obstacle to overcome and not because non-black people see me as lesser: because black people see me as lesser and that is an obstacle that I would love to see go away; because black guys don't like me being black for various reasons, being gay one of them. Being black and not really acting black according to them; being one of them and being a dude who generally goes against the whole black grain. I'm very respectful, you know, I do lots of things that people in the neighborhoods I've lived in just didn't jive with and so you know. I'm not racist. I don't think white people owe me anything. I am totally against affirmative action. Which has caused lots of arguments and almost fights against people in school. So yeah its an extra obstacle but on the black end less than the whole world front.

Additionally, Cappy and Leroy felt that because they were intelligent black men in a society that perceived them as lesser than, it was necessary for them to do whatever they could do to distance themselves from the image of being black. What was meant as acting or being black was not overtly defined by either participant. Participants had different ways of identifying with their racial/ethnic heritage. Some, such as Jake, had not developed an ethnic identity because he did not want to alienate the heritage of his parents (one was white, the other black). Leroy, like Jake, felt that it was necessary to recognize the biological and historical contributions of both parents and by focusing on one would not give a complete representation of who he was.

Some participants developed their ethnic identities by conducting personal investigations or seeking out all-black organizations to engage with. The desire to 
engage with people who thought and felt the same way as they did was resonant across several participants. Some engaged privately using the internet or close friends. Others developed their ethnic identities by hanging out with family or seeking out black peers. The most influential people during this process were family members and mentors. Dasani and Leroy both had teachers or professors who were African American who helped steer them in a more constructive direction as they developed. For the most part the participants felt that they fit within their own tweaked definitions of their ethnic identities. Others agreed that they fit some mold of what it meant to be African American but were proud to not fit within the presented norm of African Americans.

In regards to needs when developing their ethnic identities, the respondents were split. Some felt that more positive images of African Americans would be more helpful. Dasani stated,

Dasani: More positive display I guess.

MJC: of?

Dasani: Black people. I think there is, not when it comes to media or that you are not seeing the black man or woman who is graduating and is working the one job. What is glorified is the opposite of that. What you hear is the man going to jail, the gang shooting, the people that those two different things are not positive to me and that's definitely what I see the majority of the time. Where I think that balanced out was when I went to a black elementary school and predominantly black middle school; so I was around a lot of black people; so I was taught about black history and it was included at those two schools and that was a part of my life. It was nice to see these black men and women so that I could use them as a point of reference and encourage me to do better. I could do what they did. Those things were positive but it would have been nice to not only to look back to find positive things. The history was positive, the current is not positive and the future not 
as much either. So more of a history of where we are going and less of where we came from. ... When the positive seem plausible and close enough that you can actually touch it then it makes you want to be able to work for it. But it is like this is what we do. Just a little bit more positive. It is that scandal sales better and we are still you know how they have the positive shows.

This sentiment was also echoed by Cappy and Marcus, who both felt that the representation and presentation of African American males in America was onedimensionally negative. The remaining participants wanted more personal role models or friends to help them navigate their daily lives. Mark requested that he would have liked,

having someone in my life that I had during my high school years that was helping me understand my AA side of myself. During my high school, I had a mentor who ran a program that was helping AA high school students become well grounded in their background and also bringing them up from a boy to a man.

\subsubsection{Sexual Identity}

The sexual identities of men were described as either homosexual, gay, or bisexual. Leroy felt that he was gay-by-practice since he preferred to have sex with men but on occasion had female sexual partners out of courtesy. Nonetheless, all participants defined their sexual identity as having or preferring male sexual partners. When Leroy was pressed about his sexual identity, the discussion re-collapsed into his previously stated definition of gay-by-practice. It is therefore hypothesized that the need for male role models in their lives could be a key component in learning how to relate to other men in both sexual and non-sexual situations. 
Most participants realized they had attractions to people of the same gender around ages 11 to 14, and most had come out in their late teens. A few came out in their early twenties. Regardless of the label that a person selected, they all agreed that they liked and preferred to have sex with their same sex. There were variations from person to person. Most of the development of their sexual identities was done in private. Some sought out friends and peers to investigate what being gay meant. Others used the internet to find others who were developing as they were. Vince describes how he used the internet when first coming out:

I used to go to like gay chat rooms on AOL like in high school and I would chat with people.

"Hey, who are you?"

"Oh I am here."

"Send me a picture."

"No you send me a picture."

That definitely was a secret way to connect with other gay people around the country, so that is a big thing. We had AOL for a while. Watching gay porn. You kind of know that you're gay when you're watching gay porn. I would say that is a pretty good start. Gay porn and gay chatting and like even on gay hook-up sites you go on there ... if you're definitely on one of those you're probably gay. But how do they help me specifically? I guess the internet was a good way for me to maintain anonymity but still explore this gay side of myself; that for a long time, that I knew I was gay but I wasn't acting on it or pursing it. I was maintaining a straight image. It allowed the gay part of me to still grow behind closed doors. But I was still maturing, or whatever, gayly just not in the public eye.

Dasani used the internet as a safe space to explore his world without having to physically endanger himself. In his words:

The internet had the most influence for me than any other area. I used to go on these gay chat sites when I was in my early teens. And just go 
and chat; found out about cyber sex and it was interesting; and it was just interesting having contact with other people who had some of the same urges that I did. And it is the same point that you are becoming a lot more sexual. It was nice to be able to talk about that kind of thing and act out these fantasies in my head and not have the pressure of doing anything; and outing myself to the people around to how weird I am because certain people like certain things; and I would be the one to be like I like this, and people would be like "Oh my god, you are so weird." So I had to do that in private and figure out what was sexy and what does it mean. There was all of this gay lingo and what does this word mean and having to ask that. That was really cool to me. I really enjoyed that. The only thing that I used the internet for to help me identify myself. Never googled anything except this. I would just sit there and chat and tell people what turns me on and what didn't turn me on. And those things and so many different questions and I would sit by myself and figure them out later. I shouldn't have been doing it at that age but I've also been on my own for a lot of my life.

While some of the younger participants were still investigating their sexual identities, for the most part everyone had a fairly stable sexual identity.

As with their other identities, participants would have liked to have had a mentor or close friend they could have talked to when growing up. Dasani said,

I don't know what could have been helpful. I really don't know. Just someone to listen to what I had to say or how I felt about certain things. Someone to understand what I was going through. I went out at an early age and experiencing straight clubs and gay clubs... In the gay clubs being accepted by everyone so I would say it really depends on the person. I think someone to be supportive of the decisions that I made.

Others wanted more examples of different types of culturally relevant gay men that they could emulate or look up to beyond the stereotypical flamboyant hairdresser. 


\subsection{Context Identity Saliency Questionnaire Results}

A modified Context Identity Saliency Questionnaire (CISQ) was administered to the participants and combined with results from the pilot study. Figure 5.1 shows the total responses to questions based on sexual, ethnicity, and gender identity. From the plot, the most frequent response to answers was sexual identity, followed by gender and ethnic identity. This suggests that implicitly, participants favored their sexual identities over other identities, regardless of composition of environment. 


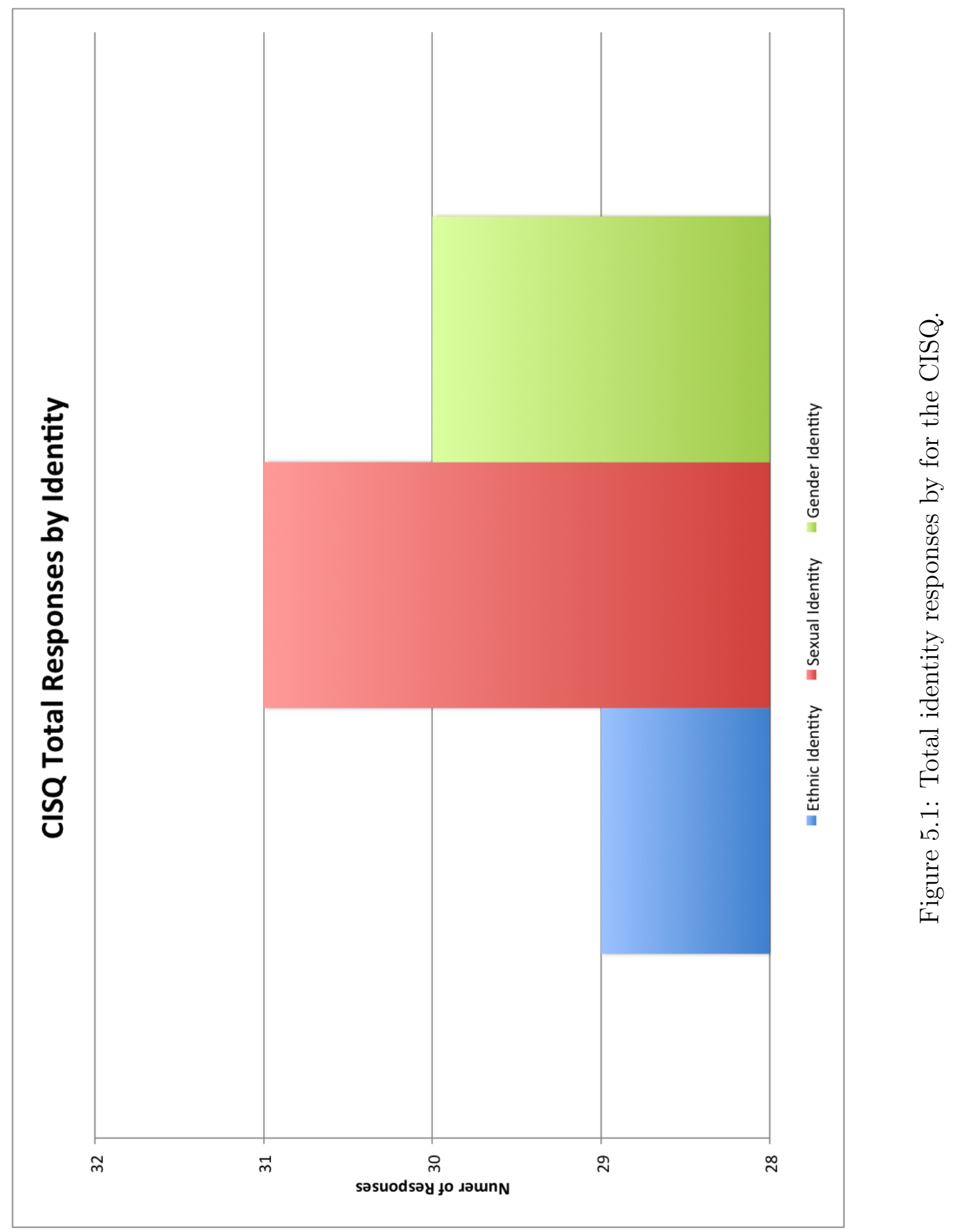




\begin{tabular}{cccccccc}
\hline & Mark & Cappy & Leroy & Vince & Dasani & Jake & Marcus \\
\hline Stated Salience & SI & GI & EI & GI & GI & SI $=$ GI $=$ EI & GI \\
Mode & EI & GI & EI & EI & GI & SI & GI \\
\hline
\end{tabular}

Table 5.1: Mode statistics comparing stated salient identity compared to the modal response to CISQ questions.

Subsequent analysis was conducted comparing the identity that was overtly stated as most salient compared to their modal response to the questions. These results are limited to the the most recent study participants and not the pilot study participants. In only three of the seven cases did the stated salient identity match the mode identity across all 12 presented contexts. A summary of modal statistics for preferred identity compared versus responded identity are presented in Table 5.1.

When presented with a situation with all white identified persons, the most salient identity in that situation was ethnic identity (six out of seven responses). When a person was in a group that shared his ethnic identity, then the most salient identities were ethnic identity and sexual identity (three and three, respectively). In a group of all gay males, the most salient identity was also ethnic identity (three out of seven). A group of all queer identified people gave a modal response of ethnic and gender identity equally (three and three). This finding is dissimilar to what was implicitly measured as the most frequent response based on environmental context of both study groups. It is possible that persons may implicitly think about their sexual identity but may use their ethnic identity to navigate within certain environments. This could be because a person's ethnic identity is readily visible 
Part I: Results

while someone's sexual identity is not easily discerned by others from observation alone. 


\section{Chapter 6}

\section{Part II: Proposed Theory}

Since no existing theory provides the variables needed for a dynamic systems approach, a new framework must be created that captures these nuances. Diamond (2007) used some dynamic systems ideas to analyze how lesbian women developed their identities. This model was useful but lacks mathematical variables, making it difficult to scale and plug in different mathematical values. This is a common critique of dynamic systems models (Lewis, 2000; van Geert, 1998, 2003; van Geert \& Steenbeek, 2005).

Taking these critiques into consideration, a new theory was developed to address these concerns. The theory was created using these ideas as parameters:

- A primary goal of adolescence is to be able to answer the questions of the self proposed by Harter (1990) and Markus \& Nurius (1986);

- The main drivers of this are environmentally specific (Spencer et al., 1997) proximal processes (Bronfenbrenner \& Morris, 1998) that change over time (Marcia, 1980);

- Changes between states should become more complex over time, an indicator of development; and, 
- A person in the quest to develop an identity goes from periods of stability to instability to stability.

Note that if a person does not reach a more complex state, he will recycle through a state of instability until a more complex stable state is reached. The new framework being proposed uses components from each of the previously reviewed theories, primarily focusing on the model of gender development by Cass (1979) as a model of cradle-to-adult development. Figure 6.1 summarizes the different parts of the proposed theory. 


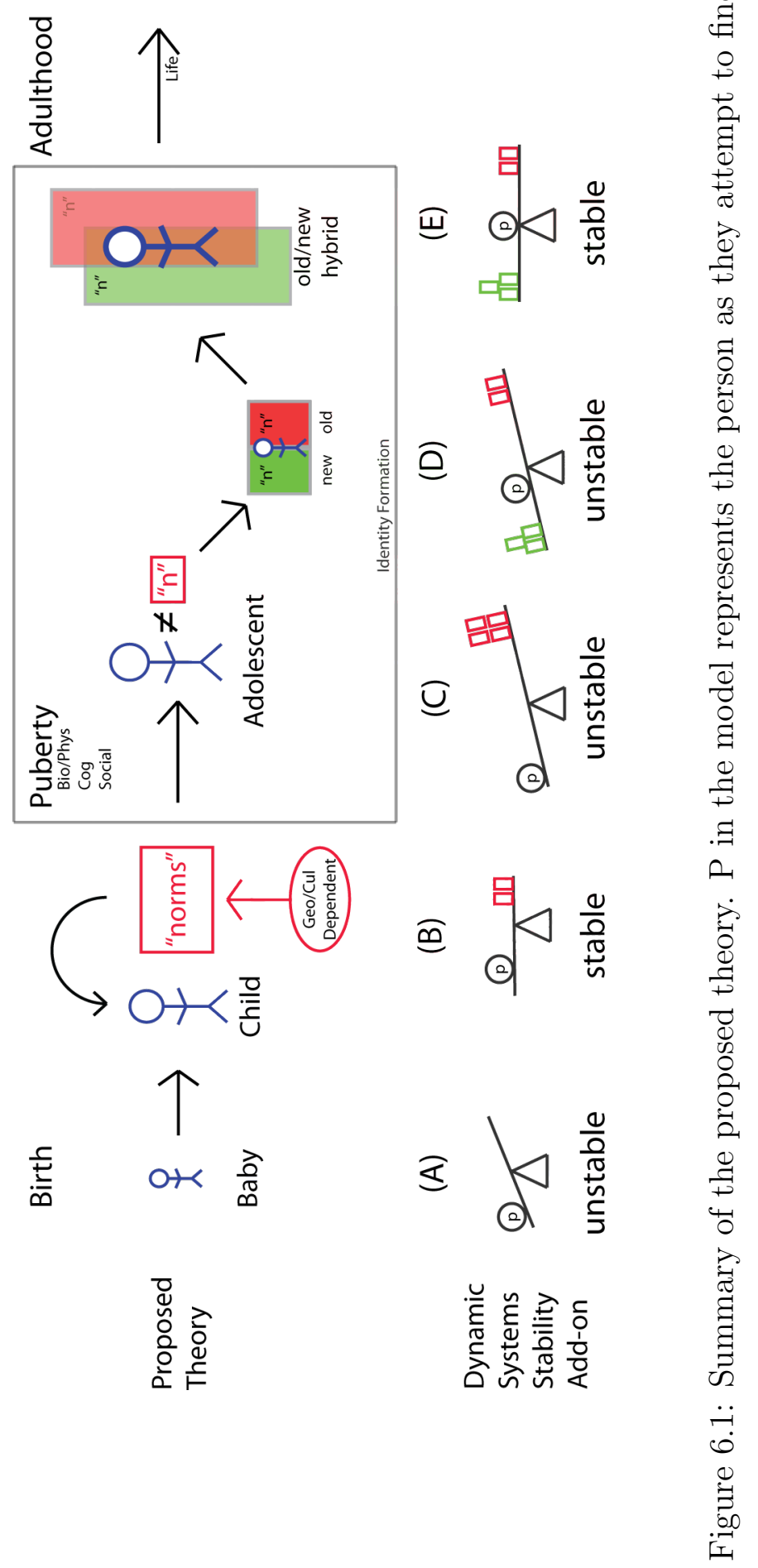




\section{Part A}

From birth, a baby is assigned a sex by physicians or family members based on observed physical features. A baby's genetic make-up helps determine what sexual characteristics are visible. This characteristic is recorded on a birth certificate and serves as a starting place for society to begin to interact with the infant. The recorded sex also loads a set of scripts to be used by others when socializing an infant. In this regard, development begins immediately at birth. Stability in this stage occurs as a baby takes in new information about its environment and is able to successfully interact with those around it.

\section{Part B}

Next, a baby enters into childhood, where it is presented with a set of acceptable norms based on its assigned sex. These norms are represented by the red squares in the dynamic stability add-on in Figure 6.1. These norms are geographically specific and unique to each culture. It is the role of the community that a child

lives in to educate and socialize a child to fit within these norms. The process of socializing a child is based on the different proximal processes to which a child is exposed. For instance, an important proximal process for a child to understand the world is to observe and track differences. Children may also make rough social comparisons between themselves and others. Figure 6.2 illustrates part B.

A key part of Figure 6.2 is that the interactions between a child and its environment are bi-directional: an environment influences the behaviors of the child and the child can have an influence over the environment's behavior. As a child 


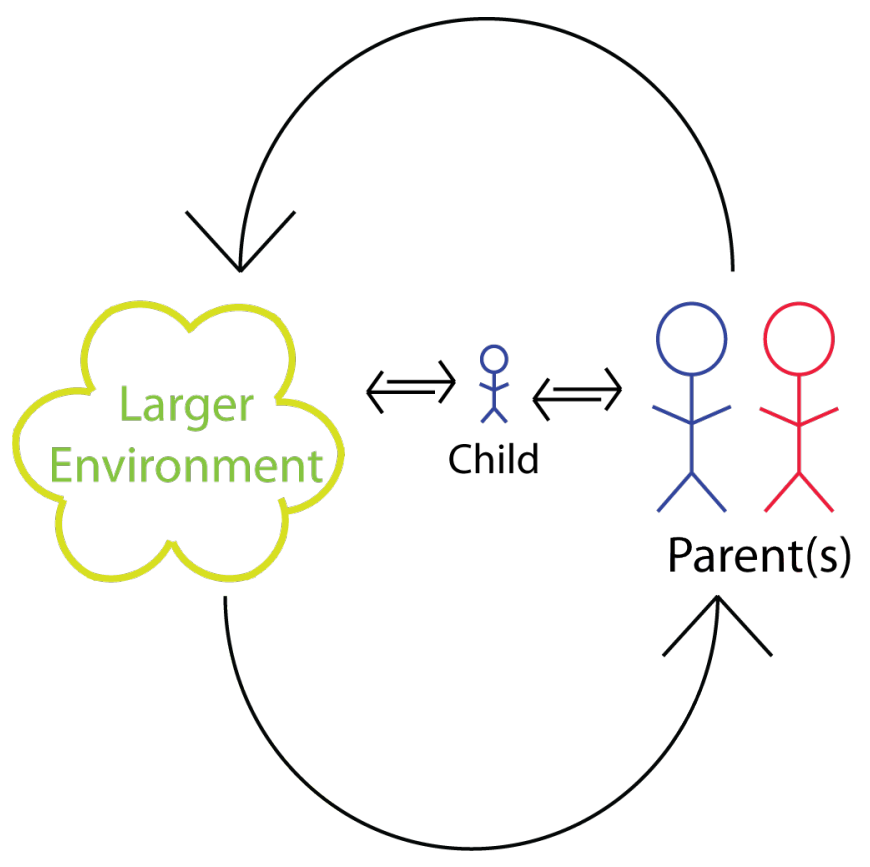

Figure 6.2: Two way interactions

develops, the environment responds by changing how it interacts with the child. An example of this is how parents generally treat children differently based on age and birth order. Parents also adjust their parenting style based on how well a child can respond to different environmental inputs. For instance, in some households, children are given small chores to complete as they become old enough and mature enough to complete them. Thus, the environment is constantly changing and adapting just as a child is developing and adapting as well. Similarly, parents may completely alter the socializing environment by changing jobs or moving to a different state. This would expose the child to a new set of norms that must be learned and adopted. 


\section{Part C}

With the onset of puberty, there are massive changes biologically and physiologically, such as growth spurts, development of secondary sex characteristics, and other changes. These chemical changes also drive changes to a child's cognitive capacity. The major cognitive changes are a byproduct of expanding cognitive capacity but also increasing cognitive loading from the environment. Stated differently, a pubescent child has increased capacity to decipher, process, and relate to the bombardment of new and novel stimuli. Adolescents can consider future narratives, idealized selves and empathize with others. In Figure 6.1, the person becomes less stable because they see themselves differently from the societal norms that have been assigned and ascribed to them from birth.

Changes to cognitive capacity leads to increased maturity, which may change how and whom an adolescent interacts with socially. A person often chooses to associate with peers with similar interests to his own or those who look the most

like himself. A changing social group and reliance on environmental peers is a big signal during the onset of puberty. This exposure to a new set of peers, better ability to process his environments, and the ability to understand himself, may create instability.

\section{Part D}

These sometimes massive changes often create tension internally. The balance between his internalized norms and the new observed norms is depicted as red and green blocks in Figure 6.1. This instability is due to an adolescent recognizing 


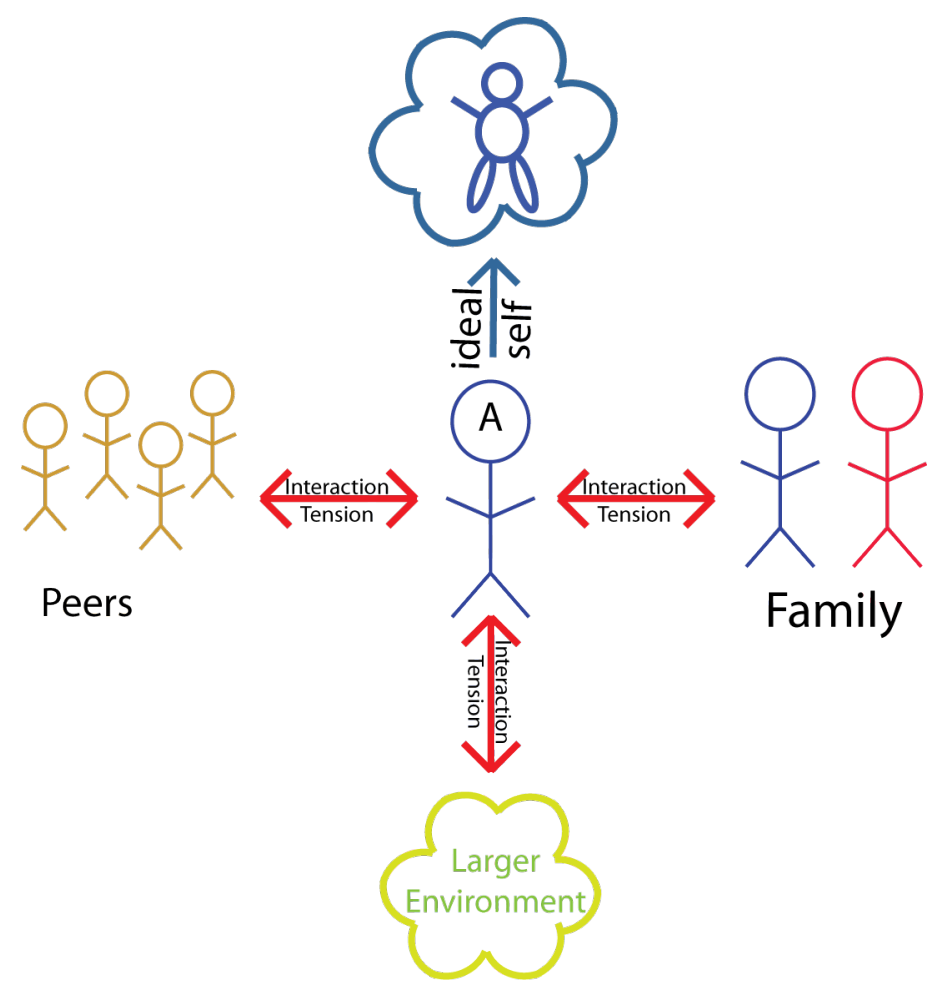

Figure 6.3: Possible sources of tension between an adolescent and different objects in his environment.

that who he wishes to be is inconsistent with the norms he has internalized. This instability is also exacerbated by negative experiences in his environment that challenge how he evaluates himself. Reconciling these negative experiences begins the process of developing an identity toward the part of himself that has been challenged as an adolescent changes his behaviors to reconcile this tension.

Another byproduct of expanding cognitive capacity is the ability to now make meaning of social comparisons from earlier stages. For example, tension may arise with the realization that males are excepted to fulfill certain roles but an adolescent does not wish to fulfill that role. Figure 6 illustrates some of the sources of tension an adolescent may experience as he interacts with the environment. Using 
Festinger's cognitive dissonance theory, a person may utilize one of three ways to relieve this tension:

- (a) changing a behavior,

- (b) changing an environmental belief, and

- (c) developing new beliefs (Festinger, 1957).

Proximal processes play a key part in re-establishing a new stable state or helping to propel a youth into a period of instability. For instance, an adolescent may take up a new hobby to reconcile the expectation of being macho or may lift weights to become more like the accepted norm of muscular men. In Figure 6.1, a person begins to jockey a position between the socialized childhood norms and the new norms he is learning to accept.

This becomes extremely important as a person attempts to reconcile his ethnic, sexual, and gender identities. How relevant and how a person attaches to each of these identities would determine how a person reconciles tension between identities. For a homosexual defined male, can he still be considered masculine? Or does sexuality stay confined simply to the act of having sex with males? For many, answering these questions is key to determining different development outcomes. More tension may arise if obtaining stability in one identity causes another identity to become unstable (Jamil et al., 2009; Poteat et al., 2009; Savin-Williams, 1994, 2001). This is the stage in which a person begins to answer the questions of "who am I?" and "who do I want to be?" (Harter, 1990). Reconciling this tension requires an adolescent to seek out new data to help reorient and stabilize his 
identity.

\section{Part E}

The final step is to re-establish stability across his entire self. This is often in the form of a hybrid old/new self. This new identity creates a large buffer, or sets of coping mechanisms to address different environmental challenges (Spencer, 2006). Additionally, the new identity shapes lenses to observe, sort, and differentiate the world around him. As a person enters into adulthood, his identities become relatively fixed; this does not mean that he cannot change how he views himself. Identities tend to be relatively fixed post-adolescence because the chemical catalysts needed for massive cognitive change are not present at the same levels as they were in adolescence. Instead, changing oneself will require undoing of many of the cognitive and behavior connections formed during the previous periods of adolescence. People who do not fully form a stable identity by the end of adolescence risk being unable to develop a cohesive definition of one-self as they move through adulthood because the biological catalysts that encourage meaning-making are not working at the same levels as they were during adolescence (Finkenauer et al., 2002; Spencer et al., 1997)

While the theory appears to be similar to other stage theories, the goal was to illustrate some of the nuances of a more detailed model of development. As varied as people are, the purpose of this theory is to not necessarily look for milestones but to observe the processes of going from stability to instability, reconciliation, and then to stability again. Development would therefore occur on two levels:

- net development, or the total change from the previous state to the current 
Part II: Proposed Theory

state, and

- instantaneous development, or the incremental changes made as the person becomes unstable and works toward stability again.

Both can be represented as a developmental change vector, allowing for movement in any direction since developmental pathways are not necessarily linear. 


\section{Chapter 7}

\section{Dynamic Systems Model of Identity}

The use of dynamic systems to model identity is a new area of focus. A few researchers (see Diamond, 2007; Thelen, 2005; van Geert \& Steenbeek, 2005) have used a few dynamic systems tools to model some processes, but these models still miss key components. At best, most attempts to use dynamic systems theory on the topic of identity development in the field of psychology were summaries of ideas to consider when developing said models. This chapters seeks to create a formal structure of identity development using dynamic systems methods and tools. To accomplish this, several tools will be integrated to create a dynamic systems model of adolescent identity development. Each tool has its own pros and cons; ultimately it is up to the modeler to choose the best tool to describe the phenomena of interest. Two tools, the causal loop, and stock and flow diagrams are used frequently by dynamic systems modelers to model interactions between objects and other phenomena. However, due to the limitations of these two models, only certain components are useful for the modeling of identity development. Therefore, a hybrid, story-like model will be utilized. This model will capture the usefulness

of each model but use descriptive language to connect the different components of the model together. This type of depiction is more accurate of how development is hypothesized to occur. 


\subsection{Causal Loop Diagrams}

Causal loop diagrams (CLDs) are used to model cyclical causality models. The key to a causal loop diagram is that each component in the model directly causes another part of the model to increase or decrease. CLDs are primarily used with systems that are seeking to maintain a stable state, such as a thermostat maintaining a temperature of a room. To maintain a steady state, CLDs utilize two types of feedback structures. Positive feedback structures add something to a variable until a certain threshold is met. Negative feedback structures remove something from a variable until a certain threshold is achieved. Regardless of the type of feedback structure, whatever is added or removed is always done at a constant rate. Often times, there is a delay between when the threshold is achieved and the deactivation of the feedback structure. In a plot of type of feedback as a function of threshold, we would observe an oscillatory nature as stability is achieved.

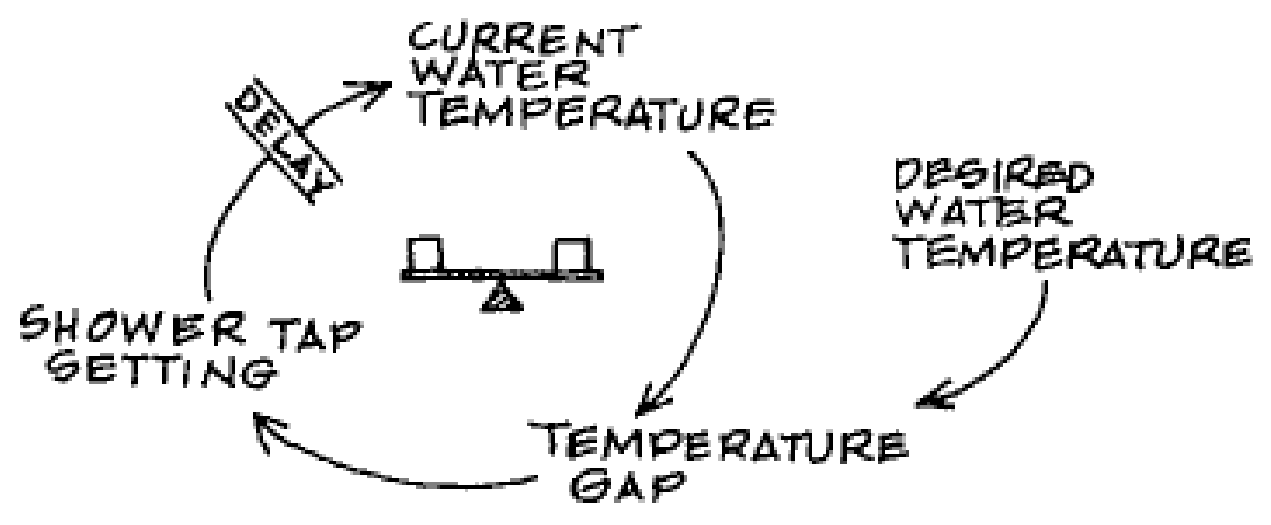

Figure 7.1: Causal loop diagram with delay for maintaining temperature. Source Senge (2006, p. 76). 


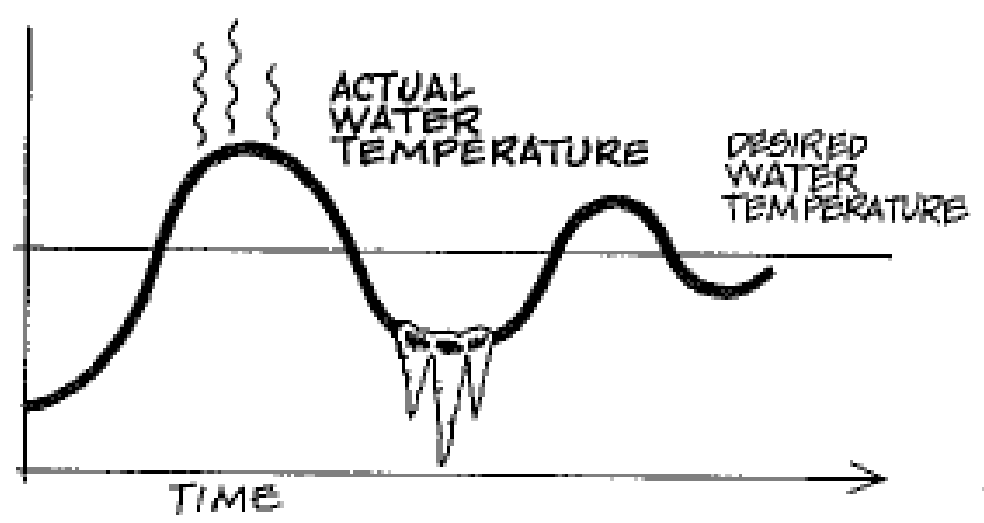

Figure 7.2: A behavior versus time plot describing the change in water temperature based on adjusting the shower tap setting to obtain a desired temperature. The oscillatory nature of the plot is caused by the delay between adjusting the shower tap and the current water temperature. Source Senge (2006, p. 76).

An example of a simple CLD model is how someone maintains a steady temperature while taking a shower. Figure 7.1 shows the complete CLD model. As the water gets cold, the hot water is turned up. After the knob is turned, there is a delay as the addition of hot water mixes with the existing volume of cold water to reach the desired temperature. As the water gets too hot, the cold water is turned up or the hot water turned down, causing another delay as the temperature is regulated. This model assumes that whatever temperature of water is added or removed is always done at a constant rate. Figure 7.2 shows the oscillatory nature as one seeks to maintain a stable water temperature. CLDs are useful tools given their ability to diagram both simple and complex systems and identify loops within these systems. 


\subsection{Stock and Flow Diagrams}

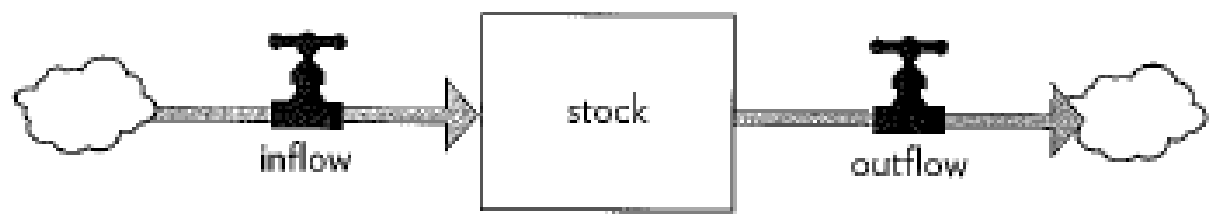

Figure 7.3: Basic archetype of a stock and flow diagram. Source Meadows (2008, p. 18).

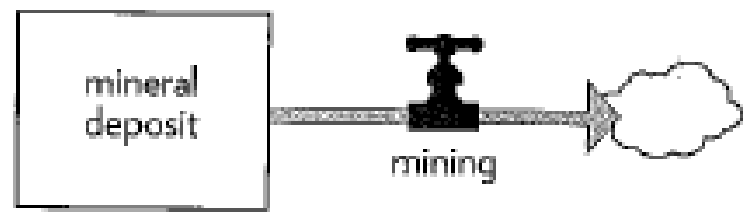

Figure 7.4: Stock and flow diagram of mining mineral deposits. The amount of minerals available is the stock with the rate of extraction being the flow. Source Meadows (2008, p. 18).

Another tool utilized is the stock and flow diagram. Figure 7.3 illustrates the components of a stock and flow diagram. A stock represents what is being counted, for example water level or amount of fuel in a gas tank (Meadows, 2008). A flow represents what is causing a stock to change. This could be the rate of water flowing into a vessel or the rate of fuel consumption per hour (Meadows, 2008). In stock and flow diagrams, there are two types of flows: inflows represent stuff flowing into a stock and outflows represent stuff flowing out of the stock. Figure 7.4 illustrates a basic stock and flow diagram of the amount of minerals in a mine as the function of mining, which depletes the amount. The cloud represents the stuff 
that is flowing out of the system. Stock and flow models are useful when you have a quantifiable item that increases or decreases at some rate. The biggest benefit to a stock and flow model is the ability to use differential equations to describe changes to a stock state over time.

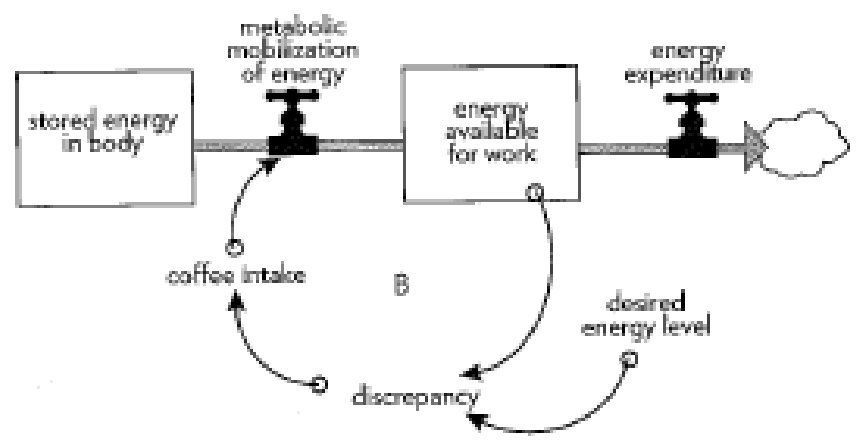

Figure 7.5: Stock and flow diagram of energy expenditure for a fixed source in the body as a function of metabolic rate from a caffeine source. Source Meadows (2008, p. 27).

Figure 7.5 illustrates a more complicated model that uses auxiliary variables to control inflows and outflows. An auxiliary variable is a value that can modulate the rate of change of a flow in a model. In figure 7.5, the discrepancy between desired energy level and the stock represent actual energy level determines how coffee influences the body's process for metabolizing energy stored in the body. In this scenario, energy flows from one stock to another stock before leaving the system, controlled by three auxiliary variables (one of which is a constant).

\subsection{Proposed Hybrid Story-like Model}

While stock and flow models are very useful, they are limited in the present theory because there is no clear stock when understanding identity, nor are there 
flows with quantifiable rates to modify the given stocks. Causal loop diagrams could be used to model identity but are difficult to implement because the looping nature of identity development is difficult to map. A common question that came up during this phase was "what is a stock?" and "what is a flow?" and where are the different loops that could contribute to how an identity is developed. Therefore a hybrid model is proposed to describe adolescent identity development.

Using the theoretical framework presented in chapter 6, a dynamic systems model of how an identity develops and functions in real life is presented next. The goal is to model the framework using a story-like model, with components drawn using causal loop and stock and flow diagrams. This diagram will then be used to describe the different interactions between a person and his environments.

To begin, the creation of an identity is modeled using a Venn Diagram shown in figure 7.6. An identity develops as a mechanism to combat negative situations that change how one evaluates oneself. The blue circle in figure 7.6 represents the person's current self and all of their attributes. This self is the self that interacts with the environment directly. The red circle represents the idealized or internalized self. The idealized self is what a person strives to be and also contains different possible persons a person could develop into. According to the theory proposed in chapter 6 , identities are created when a person's view of the self is not consistent with the outside world, meaning that a person must go through a negative evaluation from others in order for the process to begin. Therefore, the overlap between the blue and red circles, or current with ideal self, is where the identity generation occurs and is highlighted in yellow. A negative experience is 
an experience jarring enough to cause a person to observe a difference between their current self and idealized self, setting a person on the pathway to develop an identity to reconcile the tension created from that experience. The amount of

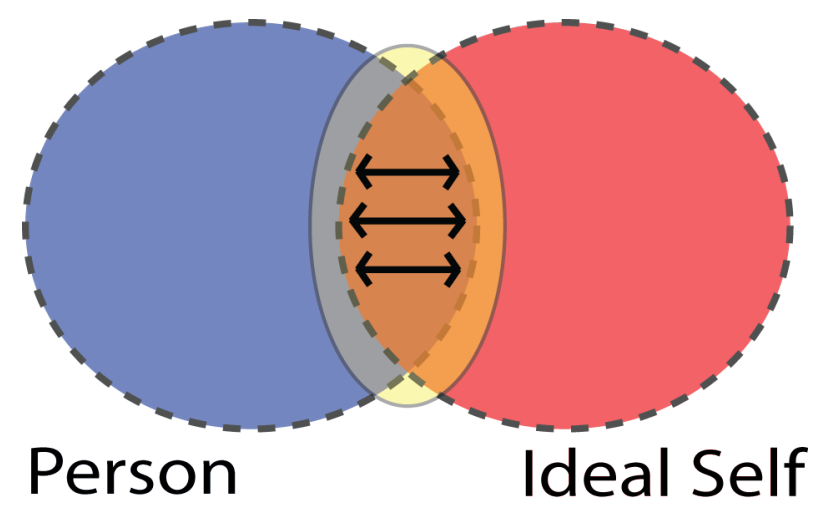

Figure 7.6: The overlap between a person and his ideal self determines the strength of a person's identity toward that part of himself. The arrows represent the interaction between a person and his ideal self as he seek to manage this overlap. The yellow highlights the overlapped region.

overlap determines the availability of tools to analyze and cope with complicated scenarios, both good and bad. In figure 7.6, these tools are represented by arrows, and correspond with the identity specific factors that are being developed. As a person becomes more comfortable and attached to his idealized self, the current self and idealized self overlap more, allowing for more ways to cope and analyze complex situations. Figure 7.7 illustrates the strength of identity as a relation of the amount overlap between the two selves, which in turn corresponds with the availability of tools to a person.

Figure 7.7 also illustrates how the amount of overlap directly correlates to a person's ability to cope and read experiences. As a consequence, the greater the overlap between the current self and the idealized self means the greater access 
to a wider variety tools to read and address different situations. The tools being developed serve as lenses and buffers between a person and the world around them. Figure 7.8 illustrates how the identity effects the lenses and buffers.
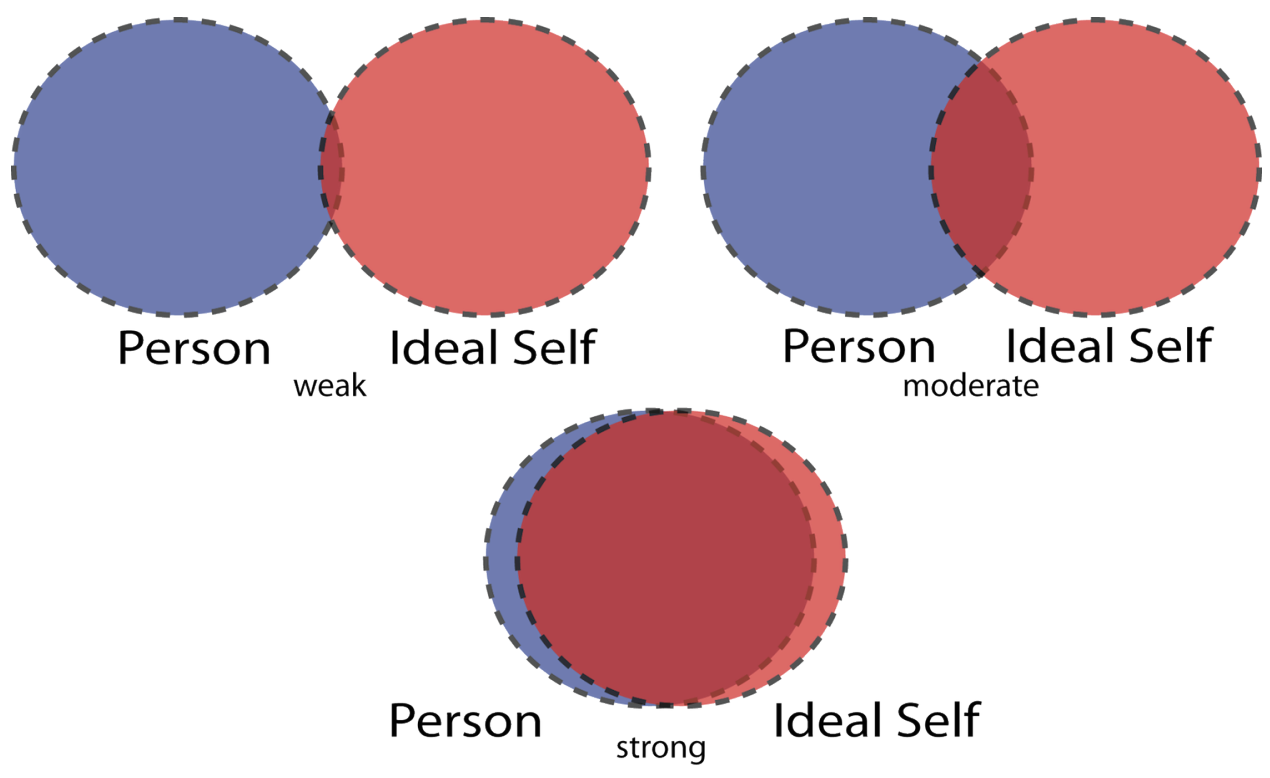

Figure 7.7: Overlap of current and possible selves as an indicator of strength of identity. The greater the overlap, the stronger a person identifies with that particularly identity.

A person's identity functions as a lens to view and interpret the world around him. The lens of a person's identity helps bring different experiences into focus. The lens is bi-directional: it helps a person focus on facets within a particular situation by making him situationally aware of dangers or resources. The lens also susses out different beneficial resources that can be used to strength a buffer or later provide a different way of viewing a situation. In this dynamic systems model, the identity shapes three different lenses:

- an interpretation lens that a person uses to understand different situations; 


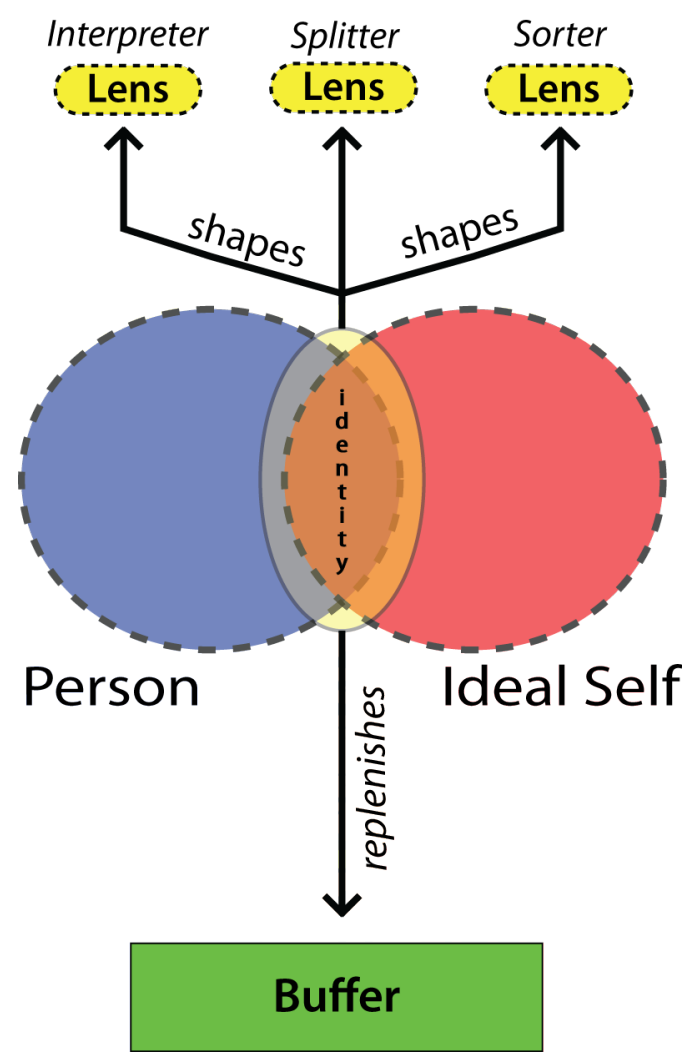

Figure 7.8: The stronger a person's identity, or greater the overlap, the more tools available to replenish one's protective buffer and to help see and shape the world around oneself.

- a splitting lens to differentiate between positive and negative experiences; and,

- the sorting lens determines whether a positive or negative experience will reinforce the person directly or his idealized self.

Next, as a person has negative experiences, his buffer learns from these experiences, gleaning useful information to be applied to similar situations in the future. The greater the amount of overlap between a person's current and ideal self, the greater his ability to generate mechanisms to cope with negative experiences, or 
buffer them. As a person constructs and modifies his ideal self, he seeks out resources to reinforce and build his identity. In the process a buffer attached to this identity is created to offset negative evaluations he may experience from the environment or from significant persons.

A buffer can consist of positive and negative coping skills. Since a buffer is used to lessen the negative experiences a person may encounter, its use is contingent upon the person's belief that one of his identities is being negatively impacted. If a person does not identify strongly with that particular ideal self, then the mechanisms for coping would not necessarily be available for use. A buffer will be depleted over time unless it is replenished. Replenishment occurs with different strategies and coping mechanisms extracted from different positive experiences from interactions with the outside world. These skills are then applied to either the current or idealized self before being integrated into an identity. As a person copes with difficult situations, he has a wider variety of skills and coping mechanisms to replenish his respective buffers, per figure 7.7.

Figure 7.9 shows the complete model of identity formation and functionality as previously described. A person interacts with the world around himself using different lenses and buffers to examine different environmental interactions. The interpreter lens is used to interpret different environments and identify possible benefits and detriments. After interpretation, different environmental interactions create experiences. These experiences are then split by the splitter lens, which interprets whether these experiences are experienced as negative or positive. This determination is based partly on how much a person identifies with his ideal self. 
If a person does not believe that a particular experience is affecting his current or idealized self, then it will not necessarily affect his identity. Positive experiences are then examined through the sorter lens, which determines if a particular experience will reinforce how a person feels about himself or his ideal self or both. The positive experiences push the person and ideal self closer together, strengthening one's identity and the availability of coping mechanisms to address negative experiences.

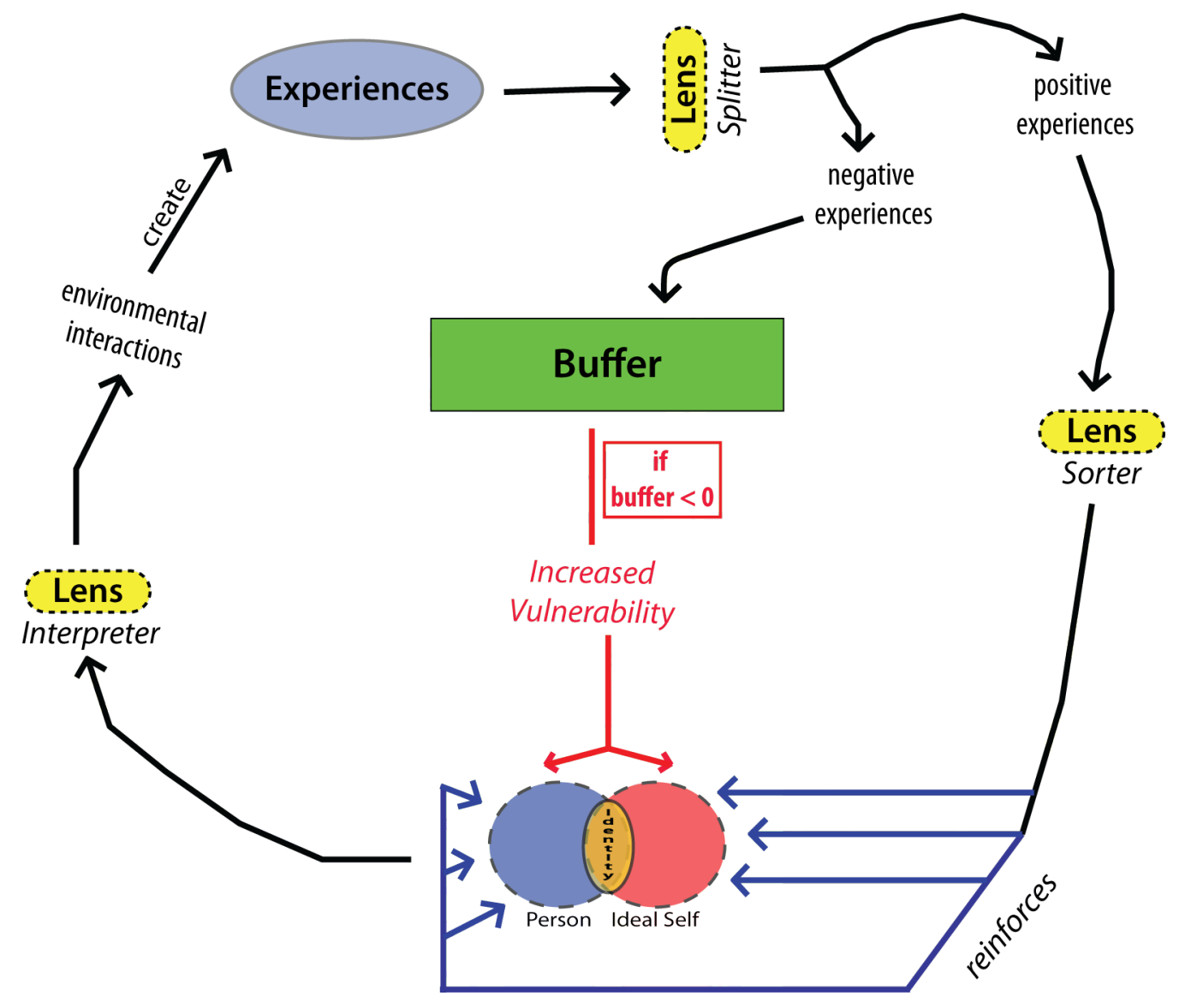

Figure 7.9: Diagram of identity formation and function. 
The negative experiences a person encounters are first moderated by a buffer. When the buffer is depleted because a person exhausts available tools to cope with a particular experience and is unable to cope, the experience can impact someone at the person, his ideal self, or both levels. This is because negative experiences pull apart the person from their ideal self, weakening their identity and decreasing the overlap between the person and their ideal self. Less overlap between the two types of selves would mean a smaller amount of identity specific tools to navigate difficult scenarios. Figure 7.10 demonstrates the increasing and decreasing of the overlap between person and ideal self and how that overlap impacts one's identity based on inputs from the sorter lens and depletion of the buffer. The weakening of an identity would cause a person stress and could increase his vulnerability to risk-taking behaviors (e.g. drug and alcohol abuse, etc.) as he copes with the stress of a negative experience. After an experience, a person may re-adjust how much he identifies with his ideal self, before the process repeats for the next experience.

The proposed dynamic systems model appears to be circular in nature but the feedback loops are not clear enough to make clean differentiations between the different types of feedback. In this respect, a buffer functions similarly to a stock but may not be may not be a stock in the strict sense because it is not possible to clearly quantify "buffer" units. As more research is done using dynamic systems theories in the field of identity development, it may be possible to create specific markers for model design. Nonetheless, the hybrid model is preferred over a pure CLD or stock and flow diagram. 


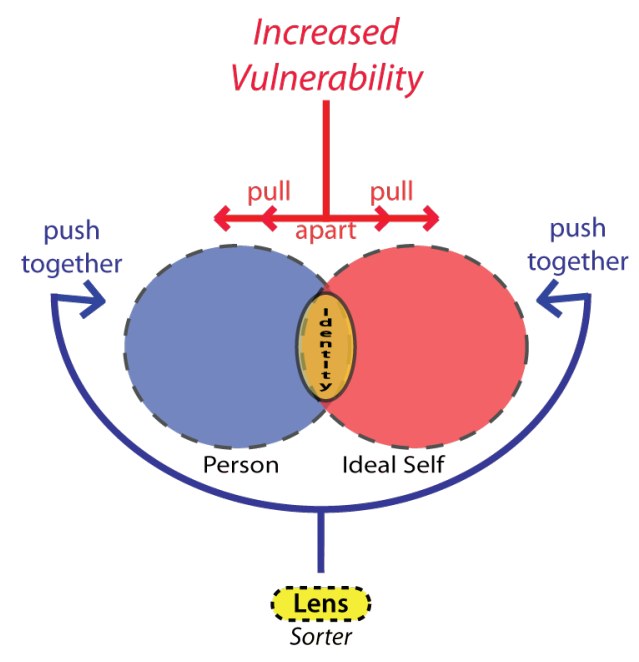

Figure 7.10: As the buffer is depleted, negative experiences decrease the overlap between the person and their ideal self, weakening their identity. Simultaneously, positive experiences through the sorter lens increase the overlap between the person and their ideal self, leading to an increase in overlap and strengthening of their identity.

\subsection{Multiple Identities}

The model presented thus far assumes that a person has one self and one ideal self, giving rise to one buffer, lens, and identity. A person will most likely contain multiple idealized selves and therefore numerous identities (which only occur at the overlap between an ideal self and the person). Each ideal self that a person has would also be an additional circle allowing for multiple identities for use throughout his life. Using the presented model, a more complicated Venn Diagram of how identities are formed would be necessary. A person could have three ideal selves giving him three different and distinct identities: a gender identity, sexual identity, and an ethnic identity. Figure 7.11 illustrates the possible overlaps between the person (the blue circle) and each ideal self: ethnic (red circle), sexual (yellow 
circle), and gender (green circle). A person would also have a core identity that encompasses the person and all of their ideal selves. This identity would represent their highest and most integrated notion of self a person possesses. This more multiple identity diagram would replace the single identity Venn Diagram presented at the bottom of figure 7.9 .

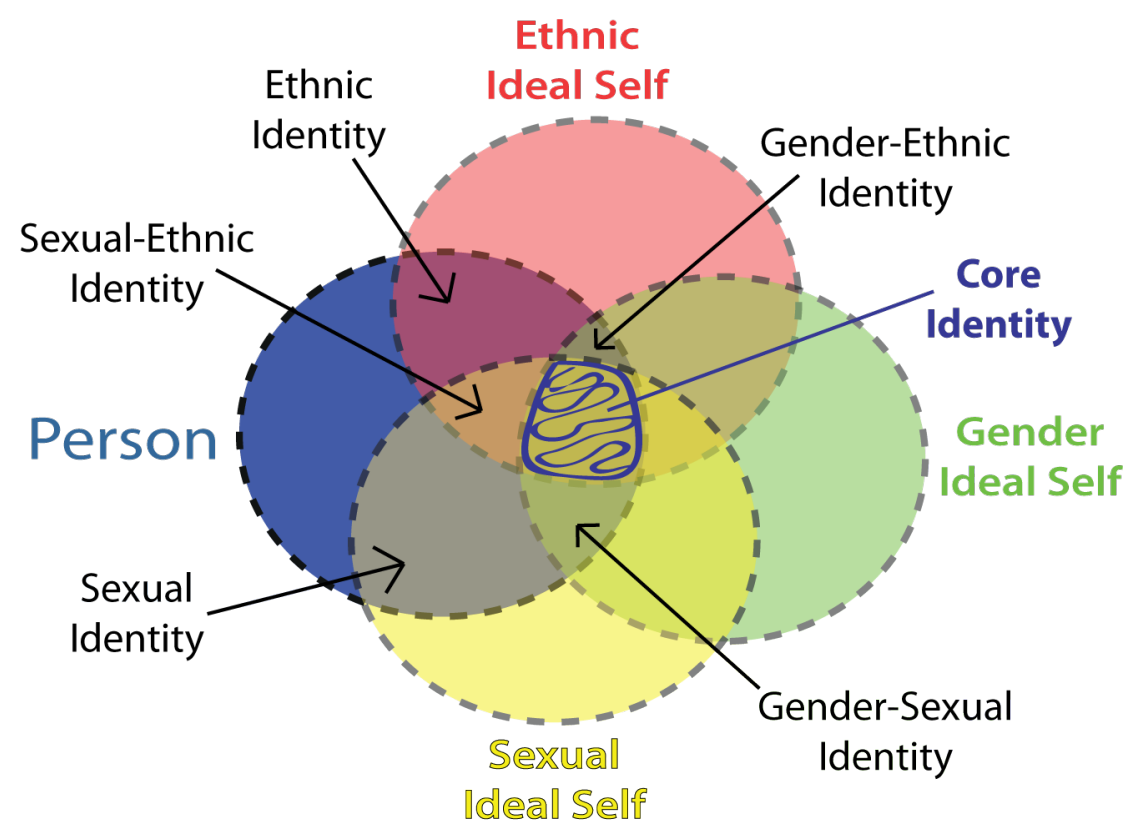

Figure 7.11: Overlapping of ideal self lenses with current the person creates balanced hybrid identities (e.g. gender-ethnic identity, etc.) represented by the overlap between the circles for ideal gender, ethnic self, and with the person.

Given the complicated nature of human behavior, it is possible and extremely likely that a person's ideal selves overlap and form hybrid selves and identities. For example, a person would most likely have a gender-sexual identity, a sexual-ethnic identity, and so forth. The numerous different identities a person may possess would then shape the different lenses he uses to see the world. 
Again, the amount of overlap between a person and their ideal ethnic, sexual, and gender selves would provides a certain amount of tools to create lens and buffers. The greater the overlap, the more tools available and vice versa. Further, the amount of overlap between a person and a particular identity also corresponds with the strength of that identity in relation to the other available identities, as depicted in figure 7.12. This figure shows not only variations in overlap between ideal selves and the person, but each identity that occurs would be weakened and strengthened by different experiences. Some of the lenses used could be environmentally sensitive, as noted from the CISQ results from chapter 5. It is possible that different lenses and buffers, and hybrid lenses and buffers for that matter, may be used to determine which identity could be used to navigate a particular environment.

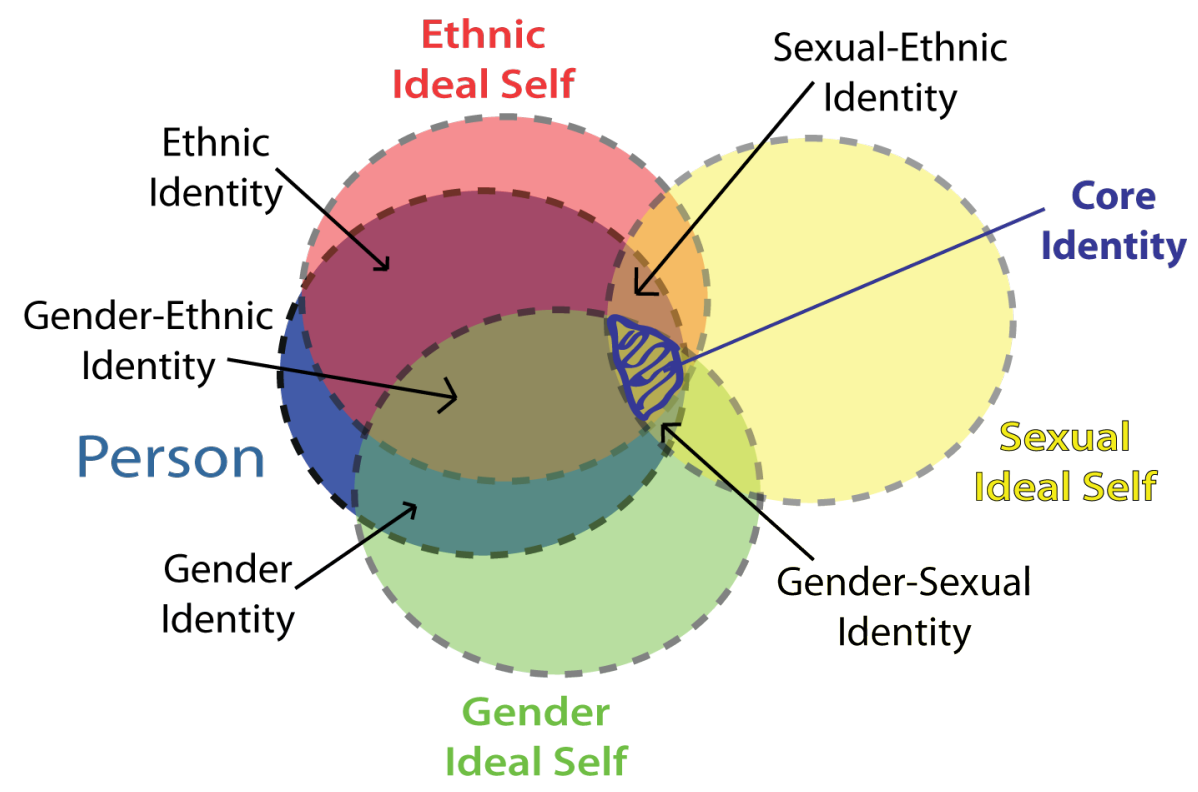

Figure 7.12: More realistic representation of the varied overlap between a person and their different ideal selves. Shaded regions represent hybrid identities. 
Using figure 7.12, we can see how experiences would alter someone's identity. For example, a self-identifying gay black male in an environment with all black males may find that his gay identity is more useful in that scenario, and would use his gay lens to understand the experiences within that environment. This would increase the overlap between the person and their sexual ideal self, strengthening that identity. When the self-identifying gay black male has a negative experience while in the same environment, the gay identity buffer would first moderate the experience until depleted. Then, the residual from that experience would push the sexual ideal self away from the person, decreasing the overlap and weakening their sexual identity.

If the buffer attached to the identity in use is depleted, then another identity may take up the slack until the depleted buffer can be restored. Simultaneously, a person may also pick a different identity to replenish a depleted buffer as he sees fit. Given the breadth of identities available, it is possible that a person will have a variety of coping mechanisms and skills at his disposal. This variety of coping mechanisms is not limited to one identity; it is completely plausible that the skills necessary to cope with ethnic discrimination could also be used to address discrimination against one's sexual identity and so forth. General forms of all coping mechanisms would most likely be stored in a person's core identity. Which skill sets are used directly depends on various factors, including personal identity, environmental conditions and several others. The stronger an identity is, the more reliant that person is on that identity (and the corresponding buffer/lens system) to buffer experiences and interact with others. 


\section{Chapter 8}

\section{Discussion and Next Steps}

Analysis of the data collected from parts 1 and 2 begins by examining the questions of interest from the beginning of the thesis, restated here, and discussed in detail in the following pages.

1. What processes do male, sexual and ethnic minorities go through as they develop their identities during adolescence? What role does the environment play in developing their identities?

2. Do each of the identities of male, sexual and ethnic minorities intersect with one another? Does the intersection of identities cause internal or external conflict? Do these identities complement each other?

3. What would a dynamic systems model of male, sexual and ethnic identity development that incorporates environmental contexts and influences (i.e. peers, other resources), and biological changes during adolescence, look like? Can a dynamic model add clarity to existing knowledge of identity development of male, sexual and ethnic minorities? Can this model be used to generate new theories that allow for a better understanding of developmental processes of male, sexual and ethnic minorities? 


\section{Question 1}

One common theme that was present from the interviews is that gay black males go through similar processes of questioning and research for their respective identities. Some participants examined how to make themselves more male. Others were focused on different aspects of their ethnic identity.

Participants in the interviews often stated how important it was to have role models in their lives that were representative of many of their identities. Some participants felt that polarized representations of minorities, be it ethnically or sexually, did not help develop their identities. However, in some situations some representation was better than no representation at all. Many participants felt that being a gay black male put them in a position where others could use them as a reference into both communities. This provoked many of the participants to learn as much as possible to ensure that they were the best stewards as possible. This was true in many of the cases but not all.

Another theme that emerged was the necessity to create an environment that was personally inclusive yet separate from the mainstream. This was done to combat the homophobia that is sometimes present in African American communities and the racism that is sometimes present in LGBTQ communities. Others described how they were sometimes invited into other spheres in which they were previously denied because they fulfilled a niche or because a person sexually objectified them.

The environment plays a huge role in shaping how a person develops, especially with respect to being a minority. The most critical point of development appeared to occur when a person 
1. recognized he was different from his peers, and

2. recognized there were no other persons around or near him that he could reference.

Some stated an opposite gender parent, family member, or mentor as a significant person in their lives; yet they still wanted a similar male role model that they could have difficult discussions with.

The role of the internet in the development of male, ethnic and sexual minorities is an area of possible research. Some of the more technically inclined participants used the internet extensively to view videos, blogs, and websites that described how a person with their similar traits could act. Others used the internet as a way to solicit sex or explore their sexual sides without facing potential ridicule from their friends and family. However, it was unclear how important or influential the internet was in their overall development. From the interviews, it appeared that face-to-face contact was often favored over the internet. Simultaneously, some participants were reluctant to overtly seek out role models to help them discover themselves.

\section{Question 2}

The question of intersectionality was investigated during the pilot study. The conclusion was that identities did not necessarily intersect and perhaps developed independently. In the follow-up study, the answer to this question was less clear. It appears that some of the identities do overlap (e.g. African American with being male, etc.) but to what extent is still unclear. Some participants abhorred 
certain identities, or components of their identities and opted to become hypermasculine, gay, etc. Others embraced the fact that their identity was more complex than an amalgamation of similar components. What was significant was how the net identity allowed them to interact and perceive the world around them. Perhaps investigating intersectionality should be discarded in favor of investigating functionality of a given identity(-ies).

Conflict of identity intersections occurred when a person was unsure of the identity or identities that they could occupy. The simple state of being uncertain about oneself was enough to cause tension between the identity intersections. How and if this tension was resolved varied from person-to-person. Nonetheless, a person was still motivated to learn more about himself and others regardless of the conclusions drawn. The few instances when identities complemented each other usually occurred as a person recognized how easy it was for him to exist within different communities. The downside is that while he could exist within different communities, he was often denied permanent membership.

From the CISQ, it is apparent that there is a hierarchy of identities that is cued up based on different environmental contexts. However, there may be bias in these responses since many of the participants may have felt compelled to only list one identity for the ranking instead of multiple. The implicit ranking of identities is something that should be investigated further.

\section{Question 3}

A hybrid story-like model was proposed to describe identity development and functional. Having a pure causal loop or stock and flow diagram appeared to be 
outside the scope of this project due to the difficult nature of how to describe the identity development process. However, the model works best to describe the interaction between the different facets of how an identity works. The new proposed theory, along with the descriptive story map how an identity functions, could serve as a solid starting point to extend previous models and develop new models. Building a dynamic systems model of identity development proved to be the most difficult part of this project. Since this project is one of the first attempts to diagram out the components of identity development, it is difficult to compare the results to existing research. One main conclusion from the dynamic systems modelling process is that development of an identity is a complicated process and requires a solid theory in order to be modelled accurately.

The dynamic systems model did help generate more questions about how an identity decides which lens(es) and buffer(s) to use based on a situation. Using the CISQ results, it is unclear how the brain selects which tools to use and when. The qualitative study suggests there must be an implicit ranking system of identities that allows some identities to have more influence than others. The difficulty still lies in how to measure and quantify different proximal processes a person may use. It is also difficult to determine to which identity a particular coping mechanism can be attributed? It is hypothesized that the underlying structure of a coping mechanism (or lens for that matter) is used as an archetype to defend against specific negative experiences. This suggests that someone who has overcome racial discrimination can also use those tools to address sexual and gender discrimination as well. Future models could build on this idea, and formulate a multi-identity 
model that allows the different identities to take over when one identity is being depleted rapidly. Perhaps the extra buffer capacity of one identity is loaned to another identity until that other identity returns to a healthy state. Creation of the dynamic systems diagram generated multiple questions to consider when this methodology is applied in future research.

\subsection{Comparison to Previous Research}

Examining findings from this research with previous studies, many of the themes that were captured in this study are consistent with results from previous studies. Participants in the study did have awareness of their different identities consistent with findings from previous research (Jamil et al., 2009; Poteat et al., 2009). This awareness centered around being different from their peers. Subsequently, an investigation into these differences began to help develop a coherent idea of self (Helms, 1990).

Youth did use local resources to help develop different ideas of themselves and the relation to their communities. However, contrary to findings from Jamil et al. (2009); Poteat et al. (2009), the use of the internet or community-based organizations varied. Some participants found that the internet was useful for the formation of certain identities rather than others. It could be that this group of individuals is less interest or motivated to use the internet compared to peers of a different background. Future research should consider deploying resources in a wide variety of methods and not just digitally. 
As stated in research by Jamil et al. (2009), there are distinct pathways of development for each identity that is developed. This is because there were different occasions that prompted the investigation of one's identity. These situations also occurred at different times, but the development itself occurred simultaneously. Since some of the basic processes of development were similar between different distinct identities, participants stated that they would have liked to have had a significant person in their lives that also held many of the identities they were attempting to form. This suggests that while the start points may differ, they do tend to converge around people and/or places that bridge the gaps between identities.

Lastly, a major strength of this study was the diversity of locations where participants were recruited. Previous research has depended heavily on recruiting individuals from community-based organizations that cater to the needs of LGBTQ youth, or organizations that cater to the needs of ethnic minorities. The participants for this study were recruited from a wide range of sources, but only half of the participants came from community organizations. While community-based organizations are a convenient method for recruiting participants, the results are often limited to those that self-identify with a particular label. This research includes people who may self-identify but have different experiences than those from these organizations and gives this study an advantage over previous studies. 


\subsection{Limitations}

The findings from this study are limited by several factors. The small sample size of participants limits the confidence of the generalizability. As seen from the pilot study, how a person conceptualizes their identity depends on a number of factors including their physical location. Future research should investigate how well the resulting model replicates affects on identity development and acquisition with additional samples. Next steps include collaboration with other identity researchers interested in sexual identity development, specifically Dr. Lisa Diamond who's research on lesbian identity development could provide data for reproducibility of the model. The use of a snowball technique helped recruit more participants and should be used in the future to recruit a more representative sample of participants on sensitive research. The wording of the flyer could also use terms such as "men who have sex with men" instead of sexual minority or gay. These terms may be repulsive or deter people from the research and feel more objectified. It was also suggested that I include a picture of myself with the flyer to show that the person interested in the research looked similar to them. The dynamic systems method showed that the development of an identity is more complicated than previously articulated. This could explain why no quantitative or qualitative methodology has been developed determining how an identity develops or functions.

\subsection{Future Research}

Future research should consider compiling a more comprehensive list of processes that adolescents go through when developing their identities. This would give a 
much broader view of how people develop. Research should also include people who live in different geographic regions. This would give a more complete picture of how adolescents navigate this tumultuous period of their lives. By having a more complete picture of how adolescents develop, it may be possible for interventionists to intervene and steer adolescents towards more productive outcomes even in the face of adversity.

Lastly, the use of dynamic systems tools in concert with quantitative measures and semi-structured interviews could provide the most complete picture of development. Dynamic systems can provide a mock-longitudinal design with the results of the quantitative measures serving as starting points. The model could be adjusted using findings from both the qualitative and quantitative measures at different time points. This type of experimental design could help reduce the resource intensity that would be needed to perform a longitudinal study, while maintaining a focus on the time dynamics. 


\section{Bibliography}

Abrajano, M. (2010). Are Blacks and Latinos Responsible for the Passage of Proposition 8? Analyzing Voter Attitudes on California's Proposal to Ban SameSex Marriage in 2008. Political Research Quarterly, 63(4), 922-932.

Bem, S. (1993). The Lenses of Gender. New Haven: Yale University Press.

Bronfenbrenner, U. \& Morris, P. A. (1998). The ecology of developmental processes. In The Ecology of Development (5th ed.). chapter 17, (pp. 993-1028). John Wiley \& Sons Inc.

Cass, V. C. (1979). Homosexual Identity Formation: A theoretical Model. Journal of Homosexuality, 4 4 (3), 219-235.

Consolacion, T. B., Russell, S. T., \& Sue, S. (2004). Sex, race/ethnicity, and romantic attractions: multiple minority status adolescents and mental health. Cultural diversity \& ethnic minority psychology, 10(3), 200-14.

Cross Jr., W. E. (1991). Shades of Black. Philadelphia: Temple University Press.

Diamond, L. M. (2007). A Dynamical Systems Approach to the Development and Expression of Female Same-Sex Sexuality. Perspectives on Psychological Science, 2 (2), 142. 
Dubé, E. \& Savin-Williams, R. (1999). Sexual Identity Development Among Ethnic Sexual-Minority Male Youths. Developmental Psychology, 35(6), 1389.

Festinger, L. (1957). A Theory of Cognitive Dissonance. Stanford: Stanford University Press.

Finkenauer, C., Engels, R., Meeus, W., \& Oosterwegel, A. (2002). Self and identity in early adolescence. In T. M. Brinthaupt \& R. P. Lipka (Eds.), Understanding early adolescent self and identity: Applications and interventions (1st ed.). chapter 2, (pp. 25-56). Albany: State University of New York Press.

Frable, D. E. (1997). Gender, racial, ethnic, sexual, and class identities. Annual review of psychology, $\underline{48}, 139-62$.

Harter, S. (1990). Self and Identity Development. In S. S. Feldman \& G. R. Elliott (Eds.), At the Threshold: The Developing Adolescent chapter 14. Cambridge: Harvard University Press.

Helms, J. E. (1990). Black and White Racial Identity. Westport: Praeger Publishers.

Herdt, G. (1990). Mistaken Gender: 5-Alpha Reductase Hermaphroditism and Biological Reductionism in Sexual Identity Reconsidered. American Anthropologist, 92(2), 433-446.

Jamil, O. B. (2010). I am the melting pot. Dissertation, DePaul University. 
Jamil, O. B., Harper, G. W., \& Fernandez, M. I. (2009). Sexual and ethnic identity development among gay-bisexual-questioning (GBQ) male ethnic minority adolescents. Cultural diversity \& ethnic minority psychology, 15(3), 203-14.

Katchadourian, H. (1980). Adolescent sexuality. The Pediatric Clinics of North America, 27(1), 17-28.

Kohlberg, L. (1966). A Cognitive-Development Analysis of Children's Sex-Role Concepts and Attitudes. In E. E. Maccoby (Ed.), The Developmenof Sex Differences (pp. 82-173). Stanford: Stanford University Press.

Lewis, M. D. (2000). The promise of dynamic systems approaches for an integrated account of human development. Child development, 71(1), 36-43.

Marcia, J. E. (1980). Identity in Adolescence. In J. Adelson (Ed.), Handbook of Adolescent Psychology chapter 5, (pp. 159-187). New York: John Wiley \& Sons.

Markus, H. R. \& Nurius, P. (1986). Possible selves. American Psychologist, 41(9), 954-969.

Meadows, D. H. (2008). Thinking in Systems: A Primer. White River Junction: Chelsea Green Publishing.

Poteat, V. P., Aragon, S. R., Espelage, D. L., \& Koenig, B. W. (2009). Psychosocial concerns of sexual minority youth: complexity and caution in group differences. Journal of consulting and clinical psychology, 77(1), 196-201.

Rosario, M., Schrimshaw, E. W., \& Hunter, J. (2004). Ethnic/racial differences in the coming-out process of lesbian, gay, and bisexual youths: a comparison 
of sexual identity development over time. Cultural diversity \& ethnic minority psychology, 10(3), 215-28.

Rotheram-Borus, M. J. \& Langabeer, K. A. (2001). Developmental Trajectories of Gay, Lesbian, and Bisexual Youths. In A. R. D'Augelli \& C. J. Patterson (Eds.), Lesbian, gay, and bisexual identities and youth: Psychological perspectives chapter 5, (pp. 97-128). New York: Oxford University Press, USA.

Savin-Williams, R. (1994). Verbal and physical abuse as stressors in the lives of lesbian, gay male, and bisexual youths: Associations with school problems, running away, substance abuse, prostitution, and suicide. Journal of Consulting and Clinical Psychology, 62(2), 261-269.

Savin-Williams, R. (1998). The disclosure to families of same-sex attractions by lesbian, gay, and bisexual youths. Journal of Research on Adolescence, $\underline{8}(1)$, 49-68.

Savin-Williams, R. (2001). Differential Developmental Trajectories: Sexual Orientation as a Context for Development. In R. C. Savin-Williams (Ed.), Mom, Dad. I'm Gay.: How Families Negotiate Coming Out chapter 2, (pp. 7-21). Washington, D.C.: American Psychological Association.

Senge, P. (2006). The Fifth Discipline. New York: Doubleday.

Spencer, M. B. (2006). Phenomenology and Ecological Systems Theory: Development of Diverse Groups. In R. Lerner \& W. Damon (Eds.), Handbook of Child Psychology chapter 15. Hoboken: John Wiley \& Sons Inc. 
Spencer, M. B., Dupree, D., \& Hartmann, T. (1997). A phenomenological variant of ecological systems theory (PVEST): A self-organization perspective in context. Development and Psychopathology, 9(4), 817-833.

Spencer, M. B. \& Markstrom-Adams, C. (1990). Identity processes among racial and ethnic minority children in America. Child Development, 61(2), 290-310.

Thelen, E. (1989). Self-Organization in Developmental Processes: Can Systems Approaches Work? In M. R. Gunnar \& E. Thelen (Eds.), Systems and Development: The Minnesota Symposia on Child Psychology chapter 3. Hillsdale: Lawrence Erlbaum Associates.

Thelen, E. (2005). Dynamic Systems Theory and the Complexity of Change. Psychoanalytic dialogues, 15(2), 255-283.

Thelen, E. \& Smith, L. B. (1998). Dynamic Systems Theories. In W. Damon \& R. M. Lerner (Eds.), Handbook of Child Psychology (5th ed.). chapter 10, (pp. 563-634). New York: John Wiley \& Sons Inc.

Troiden, R. (1979). Becoming Homosexual: A Model of Gay Identity Acquisition. Psychiatry, 42(4), 362-373.

van Geert, P. (1998). A dynamic systems model of basic developmental mechanisms: Piaget, Vygotsky, and beyond. Psychological Review, 105(4), 634.

van Geert, P. (2003). Dynamic systems approaches and modeling of developmental processes. In J. Valsiner \& K. J. Conolly (Eds.), Handbook of developmental psychology (pp. 640-672). London: Sage Publications Ltd. 
van Geert, P. \& Steenbeek, H. W. (2005). Explaining after by before: Basic aspects of a dynamic systems approach to the study of development. Developmental Review, 25(3-4), 408-442. 


\section{Appendices}


Appendix A

Interview Prompt 1 Script

Interview Prompts and Fabricated Responses for Comparisons - Script

Version 3

\section{INTRODUCTION}

I would like to tell you a little bit more about why we are conducting this interview with you today. In general, we are interested in learning more about how we can help to promote good health and wellness among gay, bisexual, and questioning adolescent males like you, especially around issues related to sexuality. In order to do this, we want to learn more how you view yourself, not just as a gay/bisexual/questioning male, but also how you view yourself in other aspects and in different settings. Since you are a young person who is part of various different communities, were hoping that you can help us to better understand how trying to achieve balance between the various communities may impact you and other young people.

As I ask you to describe your opinions and experiences, please keep in mind that there are no right or wrong answers to these questions, since people have a lot of different views on these topics. I'm simply interested in what you think 
about these different issues. I don't know exactly what its like to be in your shoes or to deal with the pressures and influences that young people like yourself are confronted with every day related to tough issues, so I am looking forward to learning more about these experiences from you. Thank you for giving me your time.

This interview should take around 60-90 minutes to complete. Any questions? If at any time you have questions or something I say is not clear, please let me know and I'll try to clarify. Are you ready to get started?

\section{WARM-UP/BUILDING RAPPORT}

Before we start talking in detail about the different factors that influence young peoples behavior, I would like to first know a little about you. Pretend that you are your best friend talking to someone that has never met you before, and then describe to that person who you are. Start off with simple characteristics like age and year in school, and then talk more about who you are as a person. Give as much or as little detail as you feel comfortable telling me this is just a way for me to get to know you better so that I will know how to best ask you the other questions in the interview.

1. What would you like me to call you during the interview?

2. How old are you?

3. How do you identify yourself in terms of your ethnic/racial identity? [EI] 
4. How do you identify yourself in terms of your sexual orientation/identity? $[\mathrm{SI}]$

5. Are you in school?

(a) If Yes - What year are you in?

(b) If No - Are you on break, have finished school, or intend on going back?

Thanks for sharing a little bit about whats going in your life right now. Now, I'd like for us to begin talking about the different aspects of yourself that make you unique.

\section{General Identity Narrative}

1. In general, what is it like being a [participant age], [EI], [SI] male?

(a) What are the benefits or positive things about being you?

(b) What are the hardships or negative things about being you?

2. How do these facets relate to one another?

\section{Ethnic/Racial Identity}

Now we are going to talk a bit about your ethnic/racial identity. Some people may feel they belong to a particular ethnic/racial group but they may vary in terms of how they connect to that group. Remember, your answers will remain confidential. Let's begin.

$\underline{\text { Meaning }}$ 
1. Earlier you mentioned that you identify as [EI] in terms of your racial/ethnic identity. What messages do you get about being [EI]?

2. Tell me some of the negative things about being a/n $[\mathrm{EI}]$.

3. Tell me some of the positive things about being a/n [EI].

4. What age did you first come out?

5. How did you go through this process?

6. Would you say this process was public or private?

7. What role did/does the internet play in developing your [EI] identity?

8. Would you say there are resources available to explore your [EI]? (resources is open for the participant to define)

9. What could be/have been more helpful when developing [EI]?

\section{$\underline{\text { Self-Identification }}$}

1. You have just told me a little bit about what it means to be [EI]. How do you fit into this? What is that like for you? How do you see yourself compared to the things you told me?

2. If they mention ways that they fit, then ask: In what ways don't you fit into what we have just talked about? What is that like for you? How are you different than the things you told me about being [EI]?

\section{Community}


1. We've been focusing on you and how you think about and define your $[\mathrm{EI}]$ ness. For the next couple of questions I would like for you to think about other people who may identify as [EI]. First, do you feel that there is $\mathrm{a} / \mathrm{n}[\mathrm{EI}]$ community [a group that shares some things in common]?

(a) If yes: Describe this community to me. How do you fit in to this?

(b) If no: Why?

2. In what ways are you connected with a [EI] community? What's that like for you?

3. How did you develop this connection? Describe from as early as you can remember.

4. Are there other ethnic/racial communities that you feel a part of or connected to? [If so,] Tell me about them.

\section{Sexual Identity}

Now we are going to talk a bit about your sexual identity. Many of these questions may sound familiar, but I will be asking them with regard to your sexuality rather than to being a/n [EI]. Remember, your answers will remain confidential. Lets begin.

\section{$\underline{\text { Meaning }}$}

1. Earlier you told me that you identify as [SI]. What messages do you get about being $[\mathrm{SI}]$ ? 
2. Tell me some of the negative things about being a/n $[\mathrm{SI}]$.

3. Tell me some of the positive things about being a/n [SI].

4. What age did you first come out?

5. How did you go through this process?

6. Would you say this process was public or private?

7. What role did/does the internet play in developing your [SI] identity?

8. Would you say there are resources available to explore your [SI] (resources is open for the participant to define)?

9. What could be/have been more helpful when developing [SI]?

\section{Self-Identification}

1. You have just told me a little bit about what it means to be [SI]. How do you fit into this? What is that like for you? How do you see yourself compared to the things you told me?

2. If they mention ways that they fit, then ask: In what ways don't you fit into what we have just talked about? What is that like for you? How are you different than the things you told me?

\section{$\underline{\text { Community }}$}

1. We've been focusing on how you think about and define your [SI]ness. For the next couple of questions I would like for you to think about other people who may identify as [SI]. First, do you feel that there is a/n [SI] community? 
(a) If yes: Describe this community to me. How do you fit in to this? Are there any other $[\mathrm{SI}]$ communities, such as an internet [SI] community?

(b) If no: Why not?

(c) If they say there is no community because there is no [SI] neighborhood or area, then say: A community can be any group that shares some things in common, even if they do not live close to each other, such as an internet community. Do you think there are some of these other kinds of $[\mathrm{SI}]$ communities?

2. In what ways are you connected with a [SI] community? What's that like for you?

3. How did you develop this connection? Describe your how you came to develop this connection, starting as early as you can remember.

Intersectionality

Now I will ask you a few questions about the intersection of your [EI] and [SI]. Remember, your answers will remain confidential. Lets begin.

1. How are your [EI] [SI] related for you at this point?Are there occasions where they come into conflict with each other? Are there occasions where they complement each other?

(a) How do/did you reconcile your [EI] and [SI]?

(b) If yes, describe that process. What did you lose? What did you gain? 
(c) If no, describe the current process. What are some difficulties you are addressing?

2. How important are labels to your identities?

3. What role did/does the internet play in developing an intersected identity?

4. Would you say there are resources available for your identity as a [EI] [SI]?

5. What could be/have been more helpful when developing your intersected identity?

This last set of open ended questions are about context identity saliency. I will name off a context and you state which identity is more salient in that context. You can respond with your [EI], [SI], with another identity, or neither. Let's begin.

- All White

- All $[\mathrm{EI}]$

- All Gay males

- All queer

- All heterosexual

- Mixture of all [EI]

- Mixture of all [SI]

- Mixture of all [EI] and [SI] 
Interview Prompt 1 Script

\section{DEBRIEFING INTERVIEW}

"Several questions in the interview asked you about personal and sensitive information. Some of the questions in the interview may have caused you to think about situations or feelings that we would like to check in with you about. I want to check in with you to make sure that when you leave here today you are feeling okay and that you are safe."

IF THE PARTICIPANT DISCUSSED SUICIDAL THOUGHT, IDEATION, OR ATTEMPTS, ASK:

"At one point in the interview, you mentioned thoughts or feelings of wanting to end your life. I want to ask you now how you are feeling, and if you are having thoughts of hurting yourself."

If answer indicates suicidal thoughts, feelings, or plan, the interviewer should say, "It's my responsibility to make sure you are safe. I need you to meet with a counselor to make sure you are safe. I will stay with you until s/he arrives." Interviewer should follow clinic/agency procedures for acute mental health referrals. Interviewer should contact supervisor immediately and stay with the participant until supervisor or mental health professional arrives.

IF THE PARTICIPANT DISCUSSED EXPERIENCING SOME FORM OF ABUSE, ASK THE FOLLOWING IF THE ABUSE IS PERPETRATED BY A CUSTODIAL PARENT OR GUARDIAN, THEN FOLLOW PROCEDURES FOR CHILD ABUSE REPORTING. 
"At one point in the interview, you mentioned someone in your life hurting you or abusing you. I would like to ask you about those experiences, to make sure you are safe and to see if you would like to talk to anyone further about what has happened. Is there anything you would like to say about anyone hurting or abusing you?"

If yes, the interviewer should say, "I'm sorry that happened to you. Its my responsibility to make sure you are safe. I would like you to meet with a counselor to make sure you are safe. I will stay with you until s/he arrives." Interviewer should follow clinic procedures for mental health and/or potential abuse referrals. Interviewer should contact supervisor immediately and stay with participant until supervisor or mental health professional arrives. In addition to mental health services/referrals, the supervisor or mental health professional will provide appropriate information regarding legal protections and services related to the abuse.

IF THE PARTICIPANT DISCUSSED HIV RISK BEHAVIORS AND EXHIBITED A LACK OF KNOWLEDGE ABOUT HIV PREVENTION:

"At one point in the interview, you mentioned doing some things that might be putting you at risk for STDs and HIV. Do you mind if I give you some information about HIV and condom use?" If they agree, proceed with giving them needed information and resources.

ASK THIS QUESTION OF ALL PARTICIPANTS, REGARDLESS OF THEIR REPORTING OF ABUSE AND/OR SUICIDAL THOUGHTS:

"Is there any (other) part of the interview you would like to discuss further?" 
If response indicates the participant is in urgent need of mental health assistance, the interviewer should follow clinic/agency procedures for acute mental health referrals. Interviewer should contact the supervisor immediately and stay with the participant until supervisor or mental health professional arrives. Otherwise, interviewer should say, "If you decide that you would like to speak with a counselor, here is a list of agencies in the community that provide this service." 


\section{Appendix B}

\section{Interview Prompt 2}

Interview Prompt for Processes Underlying the Development of Sexual, Gender, and Ethnic Identities in Adolescents - Script

Version 4 - Thesis Collection Model

\section{INTRODUCTION}

I would like to tell you a little bit more about why we are conducting this interview with you today. In general, we are interested in learning more about how we can help to promote good health and wellness among gay, bisexual, and questioning adolescent males like you, especially around issues related to sexuality. In order to do this, we want to learn more how you view yourself, not just as a gay/bisexual/questioning male, but also how you view yourself in other aspects and in different settings.

Given the relatively small ethnic and sexual minority community in Portland, Oregon, there is a risk that you may be identified based on things shared during this interview. While complete anonymity cannot be guaranteed, all efforts will be made to prevent you from being identified after the interviews are completed. Some of the safeguards in place include the use of a pseudonym and the location 
that the interviews will take place.

As I ask you to describe your opinions and experiences, please keep in mind that there are no right or wrong answers to these questions, since people have a lot of different views on these topics. I'm simply interested in what you think about these different issues. I don't know exactly what its like to be in your shoes or to deal with the pressures and influences that young people like yourself are confronted with every day related to tough issues, so I am looking forward to learning more about these experiences from you. Please note that the State of Oregon requires that any suspected or confirmed cases of child and/or elder abuse must be reported to the appropriate authorities. Further, given the possibility of being identified by your responses it is encouraged that you omit identifying parts from your responses. Thank you in advance for giving me your time.

This interview should take from one to two hours to complete. Are there any questions at this point? If at any time you have questions or something I say is not clear, please let me know and I'll try to clarify. Are you ready to get started?

\section{WARM-UP/BUILDING RAPPORT}

Before we start talking in detail about the different factors that influence young people's behavior, I would like to first know a little about you. Pretend that you are your best friend talking to someone that has never met you before, and then describe to that person who you are. Start off with simple characteristics like age 
and year in school, and then talk more about who you are as a person. Give as much or as little detail as you feel comfortable telling me this is just a way for me to get to know you better so that I will know how to best ask you the other questions in the interview.

1. Please select a pseudonym for use during this interview?

2. How old are you?

3. How do you identify yourself in regards to your gender identity? [GI]

4. How do you identify yourself in regards to your ethnic/racial identity? [EI]

5. How do you identify yourself in regards to your sexual identity? [SI]

6. Are you in school?

(a) If Yes - What year are you in?

(b) If No - Are you on break, have finished school, or intend on going back?

Thanks for sharing a little bit about what's going in your life right now. Now, I'd like for us to begin talking about the different aspects of yourself that make you unique.

\section{General Identity Narrative}

1. In general, what is it like being a [participant age], [EI], [SI] [GI]? Please limit your responses to how each of your identities interact with one another (if they do). 
Interview Prompt 2

(a) Do your identities ever come into conflict with one another? If so, how do you mentally resolve some of these conflicts? What external influences help you reconcile this tension?

(b) Do your identities ever help you in ways that having a single identity wouldn't? What external influences help you reconcile these situations?

(c) How important are labels to your identities?

(d) What function(s) does your total identity narrative serve for you? (For example: "Being a male gives me a basic set of scripts to use when interacting with my friends.")

\section{Gender Identity}

Now we are going to talk about how you think and feel about what it means to be a [GI]. Growing up we often get different messages about what boys and men should and should not do, and each person will accept some of those ideas and reject others. When I ask you the following questions I want you to think about your own thoughts and feelings about being a [GI].

\section{Meaning}

1. Earlier you mentioned that you identify as [GI] in terms of your gender identity. What does it mean to you to be a [GI]?

2. What age did you first realize that you were a [GI]?

3. How did you go through this process? 
Interview Prompt 2

4. Would you say this process was public or private?

5. Who was influential in helping you develop your [GI]?

6. What role did/does the internet play in developing your [GI] identity?

7. What could be/have been more helpful when developing [GI]?

\section{Self-Identification}

You have just told me a little bit about what it means to be [GI].

1. How do you see yourself compared to the things you told me about being $\mathrm{a}(\mathrm{n})[\mathrm{GI}] ?$

2. What is that like for you?

3. What function(s) does your [GI] for you compared to if you did not have $\mathrm{a}(\mathrm{n})[\mathrm{GI}]$ at all?

Ethnic/Racial Identity

Now we are going to talk a bit about your ethnic/racial identity. Some people may feel they belong to a particular ethnic/racial group but they may vary in terms of how they connect to that group. Remember, your answers will remain confidential. Let's begin.

\section{Meaning}

1. Earlier you mentioned that you identify as [EI] in terms of your racial/ethnic identity. What does it mean to be a [EI]? 
Interview Prompt 2

2. What age did you first realize you were $[\mathrm{EI}]$ ?

3. How did you go through this process?

4. Would you say this process was public or private?

5. Who was influential in helping you develop your [EI]?

6. What role did/does the internet play in developing your [EI] identity?

7. What could be/have been more helpful when developing [EI]?

\section{Self-Identification}

You have just told me a little bit about what it means to be [EI].

1. How do you see yourself compared to the things you told me about being $\mathrm{a}(\mathrm{n})[\mathrm{EI}]$ ?

2. What is that like for you?

3. What function(s) does your [EI] for you compared to if you did not have a(n) $[\mathrm{EI}]$ at all?

Sexual Identity

Now we are going to talk a bit about your sexual identity. Many of these questions may sound familiar, but I will be asking them with regard to your sexuality rather than to being a/n [SI]. Remember, your answers will remain confidential. Let's begin. 
Interview Prompt 2

\section{Meaning}

1. Earlier you mentioned that you identify as [SI] in terms of your sexual identity. What does it mean to you to be a [SI]?

2. What age did you first realize that you were a $[\mathrm{SI}]$ ?

3. How did you go through this process?

4. Would you say this process was public or private?

5. Who was influential in helping you develop your $[\mathrm{SI}]$ ?

6. What role did/does the internet play in developing your [SI] identity?

7. What could be/have been more helpful when developing [SI]?

\section{Self-Identification}

You have just told me a little bit about what it means to be [SI].

1. How do you see yourself compared to the things you told me about being $\mathrm{a}(\mathrm{n})[\mathrm{SI}] ?$

2. What is that like for you?

3. What function(s) does your [SI] for you compared to if you did not have a(n) [SI] at all?

Last Question:

1. Would you say that any of your identities is more important than the other? 
2. Now, I am going to provide different environments and I want you to rank your identities in order of most relevant to least relevant. (For instance, say you identify as a male, asexual mexican and you are in an environment with all White people of various other sexual and/or gender identities, which of your identities would be at the forefront of your mind? Which identities would be secondary and tertiary?)

- All White

- All [EI]

- All [SI] [GI]

- All queer

- Opposite [SI]

- Mixture of all [EI] but different [SI] and genders

- Mixture of all [EI] but different [SI] and all male identified

- Mixture of all [EI] but different [SI] and all female identified

- Mixture of all [SI] but different [EI] and genders

- Mixture of all [SI] but different [EI] and all male identified

- Mixture of all [SI] but different [EI] and all female identified

- Mixture of all [EI] and [SI] and genders

\section{DEBRIEFING INTERVIEW}

"Several questions in the interview asked you about personal and sen-

sitive information. Some of the questions in the interview may have 
Interview Prompt 2

caused you to think about situations or feelings that we would like to check in with you about. I want to check in with you to make sure that when you leave here today you are feeling okay and that you are safe."

IF THE PARTICIPANT DISCUSSED SUICIDAL THOUGHT, IDEATION, OR ATTEMPTS, ASK:

"At one point in the interview, you mentioned thoughts or feelings of wanting to end your life. I want to ask you now how you are feeling, and if you are having thoughts of hurting yourself."

If answer indicates suicidal thoughts, feelings, or plan, the interviewer should say, "It's my responsibility to make sure you are safe. I need you to meet with a counselor to make sure you are safe. I will stay with you until s/he arrives." Interviewer should follow clinic/agency procedures for acute mental health referrals. Interviewer should contact supervisor immediately and stay with the participant until supervisor or mental health professional arrives.

IF THE PARTICIPANT DISCUSSED EXPERIENCING SOME FORM OF ABUSE, ASK THE FOLLOWING IF THE ABUSE IS PERPETRATED BY A CUSTODIAL PARENT OR GUARDIAN, THEN FOLLOW PROCEDURES FOR CHILD ABUSE REPORTING.

"At one point in the interview, you mentioned someone in your life hurting you or abusing you. I would like to ask you about those experiences, to make sure you are safe and to see if you would like to talk to anyone further about what has happened. Is there anything you would like to say about anyone hurting or abusing you?" 
If yes, the interviewer should say, "I'm sorry that happened to you. It's my responsibility to make sure you are safe. I would like you to meet with a counselor to make sure you are safe. I will stay with you until s/he arrives." Interviewer should follow clinic procedures for mental health and/or potential abuse referrals. Interviewer should contact supervisor immediately and stay with participant until supervisor or mental health professional arrives. In addition to mental health services/referrals, the supervisor or mental health professional will provide appropriate information regarding legal protections and services related to the abuse.

IF THE PARTICIPANT DISCUSSED HIV RISK BEHAVIORS AND EXHIBITED A LACK OF KNOWLEDGE ABOUT HIV PREVENTION:

"At one point in the interview, you mentioned doing some things that might be putting you at risk for STDs and HIV. Do you mind if I give you some information about HIV and condom use?" If they agree, proceed with giving them needed information and resources.

ASK THIS QUESTION OF ALL PARTICIPANTS, REGARDLESS OF THEIR REPORTING OF ABUSE AND/OR SUICIDAL THOUGHTS:

"Is there any (other) part of the interview you would like to discuss further?"

If response indicates the participant is in urgent need of mental health assistance, the interviewer should follow clinic/agency procedures for acute mental health referrals. Interviewer should contact the supervisor immediately and stay with the participant until supervisor or mental health professional arrives. Otherwise, 
Interview Prompt 2

interviewer should say, "If you decide that you would like to speak with a counselor, here is a list of agencies in the community that provide this service." 


\section{Appendix C}

\section{Institutional Review Board Consent Form}

Informed Consent Form for Processes Underlying the Development of Sexual, Gender, and Ethnic Identities in Adolescents

You are invited to participate in a research study conducted by Miles Crumley from Portland State University, Office of Graduate Studies. The researcher hopes to learn about the processes that adolescents go through when developing their sexual, gender, and ethnic identities. This study is conducted in partial fulfillment of the requirements for a master's degree and is being supervised by Dr. Dalton Miller-Jones and Dr. Wayne Wakeland. You were selected as a possible participant in this study because of your stated identities.

If you decide to participate, you will be asked to answer a series of interview questions detailing the processes and contexts that you went through to develop your identities. The interview should take between one to two hours to complete. The interview will be recorded and transcribed for analysis of the processes and outcomes based on different developmental contexts. Given the relatively small ethnic and sexual minority community in Portland, Oregon, there is a risk that you may be identified based on things shared during this interview. While complete anonymity cannot be guaranteed, all efforts will be made to prevent you from 
being identified after the interviews are completed. Some of the safeguards in place include the use of a pseudonym and the location that the interviews will take place.

While participating in this study, it is possible that you may experience discomfort retelling experiences from your childhood and you will only be asked to provide responses that are within your comfort zone; if a question is determined to be too personal you may elect to not answer the question at all. Please note that the State of Oregon requires that any suspected or confirmed cases of child and/or elder abuse must be reported to the appropriate authorities. You may not receive any direct benefit from taking part in this study, but the study may help to increase knowledge which may help others in the future. Findings from this study may be used by other researchers to develop different ways of intervening different periods of adolescence.

Any information that is obtained in connection with this study and that can be linked to you or identify you will be kept confidential. While a short general description of you will be used in a thesis, future journal articles, and any presentations related to this research topic, a pseudonym will be used in place of your real name. Further, after the audio is transcribed, the audio will be destroyed; the only copy of the interview will be the transcribed copy of the audio. This information will be kept confidential after transcribing and will only be stored on a single computer which will be stored in a secure location and all files will be password protected. 
Your participation is voluntary. You do not have to take part in this study, and it will not affect your participation in any courses you are taking at Portland State University. You may also withdraw from this study at any time without affecting your course grade or relationship with Portland State University.

If you have concerns or problems about your participation in this study or your rights as a research subject, please contact the Human Subjects Research Review Committee, Office of Research and Sponsored Projects, Portland State University, PO Box 751, Portland, OR 97207, 503-725-4288 / 1-877-480-4400. If you have questions about the study itself, contact Miles Crumley at 503-747-8044 or crumleym@pdx.edu.

Your signature indicates that you have read and understand the above information and agree to take part in this study. Please understand that you may withdraw your consent at any time without penalty, and that, by signing, you are waiving any legal claims, rights or remedies. The researcher will provide you with a copy of this form for your own records. 
Appendix D

Recruit Flyer

\section{Development of Identities Research Study Be a part of an important Identity Development Study}

- Are you between 18 and 27 years of age?

- Do you self-identify as male?

- Do you self-identify as Black or African-American (non-immigrant)?

- Do you self-identify as Gay, Bisexual, Transgendered, Asexual, Queer, and/or Questioning?

If you answered YES to these questions you may be eligible to participate in a confidential research study on identities.

The purpose of this research study is to better understand the processes that are involved in the development of identities of sexual and ethnic minority males during adolescence and early adulthood. The main benefit for participants in this study is the opportunity to share your story anonymously with others allowing for the a more inclusive understanding of development within minority communities. 
The findings from the study may be used by future researchers to find ways to better allocate resources for groups traditionally underserved. Participants will receive no monetary compensation for participating.

Data will be collected during a one to two hour confidential interview conducted at a neutral location at a mutually convenient time of the day. Interviews will be audio recorded and transcribed into text and pseudonyms will be assigned to participants. All identifying information will be removed from the interviews during transcription and the audio will be destroyed after transcription.

Male adolescents (ages 18-27) who self-identify as a Black or African American (non-immigrant) and as a sexual minority (Gay, Bisexual, Transgendered, Asexual, Queer, Questioning) are eligible. This study is being conducted at Portland State University.

Please email Miles Crumley at crumleym@pdx.edu or call/text 503-389-0436 to participate or for more information. 